\title{
The dispersion characteristics of air pollution from the world's megacities
}

\author{
M. Cassiani, A. Stohl, and S. Eckhardt \\ 1-NILU, Norwegian Institute for Air Research, 2027, Kjeller, Norway \\ Correspondence to: M. Cassiani (mc@nilu.no) \\ Received: 7 June 2012 - Published in Atmos. Chem. Phys. Discuss.: 5 October 2012 \\ Revised: 20 May 2013 - Accepted: 17 June 2013 - Published: 10 October 2013
}

\begin{abstract}
Megacities are extreme examples of the continuously growing urbanization of the human population that pose (new) challenges to the environment and human health at a local scale. However, because of their size megacities also have larger-scale effects, and more research is needed to quantify their regional- and global-scale impacts. We performed a study of the characteristics of pollution plumes dispersing from a group of 36 of the world's megacities using the Lagrangian particle model FLEXPART and focusing on black carbon (BC) emissions during the years 2003-2005. $\mathrm{BC}$ was selected since it is representative of combustionrelated emissions and has a significant role as a short-lived climate forcer. Based on the $\mathrm{BC}$ emissions two artificial tracers were modeled: a purely passive tracer and one subject to wet and dry deposition more closely resembling the behavior of a true aerosol. These tracers allowed us to investigate the role of deposition processes in determining the impact of megacities' pollutant plumes. The particles composing the plumes have been sampled in space and time. The time sampling allowed us to investigate the evolution of the plume from its release up to 48 days after emission and to generalize our results for any substance decaying with a timescale sufficiently shorter than the time window of 48 days. The physical characteristics of the time-averaged plume have been investigated, and this showed that, although local conditions are important, overall a city's latitude is the main factor influencing both the local and the regional-to-global dispersion of its pollution. We also repeated the calculations of some of the regional-pollution-potential metrics previously proposed by Lawrence et al. (2007), thus extending their results to a depositing scalar and retaining the evolution in time for all the plumes. Our results agreed well with their previous results despite being obtained using a totally different mod-
\end{abstract}

eling framework. For the environmental impact on a global scale we focused on the export of mass from the megacities to the sensitive polar regions. We found that the sole city of Saint Petersburg contributes more to the lower-troposphere pollution and deposition in the Arctic than the whole ensemble of Asian megacities. In general this study showed that the pollution of urban origin in the lower troposphere of the Arctic is mainly generated by northern European sources. We also found that the deposition of the modeled artificial BC aerosol in the Antarctic due to megacities is comparable to the emissions of $\mathrm{BC}$ generated by local shipping activities. Finally multiplying population and ground level concentration maps, we found that the exposure of human population to megacity pollution occurs mainly inside the city boundaries, and this is especially true if deposition is accounted for. However, some exceptions exist (Beijing, Tianjin, Karachi) where the impact on population outside the city boundary is larger than that inside the city boundary.

\section{Introduction}

More than $50 \%$ of the human population is living in urban areas (United Nations Population Fund report unit http://www. unfpa.org/swp/2007/english/introduction.html) and this fraction is still increasing, although urban areas currently cover only $0.5 \%$ of the Earth's land area (Schneider et al., 2009). Extreme examples of urbanization are the so-called megacities with a population of several millions of people; ten million are often used as a threshold to define a megacity (Gurjar and Lelieveld, 2005). This large concentration of human activity causes unprecedented pressure on the environment, including the quality of air both inside the city (e.g., Gurjar et 
al., 2008) and on a regional and global scale. Some case studies (e.g., Guttikunda et al., 2003; Stohl et al., 2003; Real et al., 2008; Mena-Carrasco et al., 2009; Voss et al., 2010) have investigated regional and long-range transport of megacity plumes and the associated chemical processes, but more must be done to quantify the relative importance of their local versus large-scale impacts.

In a relatively recent paper Lawrence et al. (2007), called L07 in the remainder of the paper, investigated the differences and common features in the regional dispersion characteristics of plumes from a collection of the world's largest cities. In that work three artificial tracers, with a characteristic decaying time of 1,10 and 100 days, were released and transported using a 3-D global Eulerian chemistry transport model. This study gave significant information on the common regional features of dispersion from these megacities and identified cases where the dispersion was dominated by local conditions. It is well known that for studying dispersion characteristics of plumes originating from a relatively localized source, a modeling approach based on 3-D Lagrangian particle models is a viable alternative to Eulerian models. Lagrangian models minimize artificial numerical diffusivity effects and can account for various subgrid-scale processes in an accurate way. On the other end, the Lagrangian nature of the model does not make it well suited to investigate the influence of the background on local megacity conditions, and this aspect is not considered here, although it can be an important aspect of the local pollution within the megacities, as recently discussed in Butler et al. (2012) and Crippa et al. (2013).

Based on these premises we decided to use the Lagrangian particle model FLEXPART (Stohl et al., 2005) for simulating the dispersion from a group of the world's megacities during the years 2003-2005, as established within the framework of the European Union project MEGAPOLI (Megacities: Emissions, urban, regional and Global Atmospheric POLlution and climate effects, and Integrated tools for assessment and mitigation, http://megapoli.info/). Our investigation has a similar scope as the study of L07 but uses a Lagrangian particle model with a 4-D sampling grid. The extension of the grid into the time domain allowed the use of additional metrics to describe the dispersion process of the plumes. Moreover, we specifically investigate long-range transport into the sensitive polar regions and into the upper layer of the troposphere and the stratosphere. Finally, we answer some of the questions pointed out by L07 by investigating the behavior of a passive tracer versus an aerosol-like tracer subject to removal processes by dry and wet deposition, and inferring information about population exposure by combining modeled near-ground concentration and population maps.

We mention that for this study, which compares several metrics for many megacities, only a modeling approach seems feasible. Consistent measurements collected for all megacities are unavailable to date. Moreover in this study the plumes are followed across many scales, and such plumes cannot be isolated in a straightforward way, in measurement data, from emissions from larger regions. Therefore, a detailed comparison with measurements for every megacity seems unfeasible and is not part of this study. Apart from the already mentioned L07, a pure modeling approach to study various impacts of emissions from an ensemble of the world's megacities has been used in several recent studies: Butler et al. (2009) studied the impact of megacities on global atmospheric chemistry, Butler et al. (2012) the megacities' ozone air quality under different future scenarios, Folberth et al. (2012) the influence of megacities on global radiative forcing, and Kunkel et al. (2012) investigated the global remote deposition of aerosol originating from megacities with an analysis similar to that of L07. Kunkel et al. (2012) in particular used five monomodal aerosols with diameters ranging from $0.1 \mu \mathrm{m}$ to $10 \mu \mathrm{m}$ and obtained similar deposition patterns for all the aerosols smaller than $2.5 \mu \mathrm{m}$.

In the next section a brief description of the FLEXPART model, the emission inventory and the meteorological input data will be given. In Sect. 3 the mean transport characteristics of the megacity plumes will be discussed. In Sect. 4 some metrics originally proposed by L07 will be calculated and compared with their original results. The contribution of megacities to pollution in the polar regions will be investigated in Sect. 5. In Sect. 6, a metric of the large-scale versus local impacts of a megacity on human population will be defined.

\section{Methods}

\subsection{Model description}

For this study, the Lagrangian particle dispersion model FLEXPART (Stohl et al., 2005) was run for the period November 2002 to December 2005. FLEXPART is a widely used transport model and has been extensively validated with measurements. Some examples of validation relevant to the present study are against (1) large-scale tracer experiments in Stohl et al. (1998), (2) aircraft measurements of a large-scale intercontinental megacity pollution plume in Stohl et al. (2003), (3) aircraft measurements of a pollution plume transported from eastern Asia to Europe in Stohl et al. (2007), (4) an in situ observation of Asian pollution transported into the Arctic lowermost stratosphere in Roiger et al. (2011) and (5) a measurement of the transport of American megacity pollution into the North Atlantic in Neuman et al. (2006). The code and the documentation are freely available (see http://transport.nilu.no/flexpart/). It is worth recalling here that (i) FLEXPART uses the well-mixed criteria, introduced by Thomson (1987), to define stochastic differential equations with a Gaussian velocity distribution to simulate the effect of planetary boundary layer turbulence on particle dispersion and accounts for the vertical air density gradient (Stohl and Thomson, 1999), (ii) it includes a 
horizontal mesoscale meandering parameterization through an additional Langevin equation for the mesoscale velocity, (iii) it simulates convective exchanges using the scheme of Emanuel and Zivkovic-Rothman (1999), and (iv) the model includes dry/wet deposition processes. Thanks to the Lagrangian particle representation the model does not suffer from significant numerical diffusivity and the grid is used only to extract information from the particle field, which in general preserves very well any flow structures generated during the advection and dispersion process. This last characteristic, and the superior accuracy in the representation of subgrid dispersion processes, differentiates this class of models from Eulerian (fully grid-based) chemistry transport models, and makes FLEXPART particularly suitable to study dispersion from localized sources in the planetary boundary layer.

The model is driven here by operational meteorological data from the European Centre for Medium-Range Weather Forecasts (ECMWF) retrieved with a horizontal resolution of $1^{\circ} \times 1^{\circ}$ and with 60 vertical levels in a hybrid coordinate system and a time resolution of $3 \mathrm{~h}$. The model output grid has a horizontal resolution of $1^{\circ} \times 1^{\circ}$ and 25 vertical levels ranging from $100 \mathrm{~m}$ in the layer closest to the ground to $3 \mathrm{~km}$ at an elevation above ground of $27-30 \mathrm{~km}$. The grid extends also in the time space, thus partitioning the particles among 10 time (age) classes based on the time elapsed since the particle release, i.e., the time of emission. The age class durations used are expressed in days as $0 \leq t<1,1 \leq t<3,3 \leq t<6,6 \leq t<9,9 \leq t<$ $14,14 \leq t<20,20 \leq t<27,27 \leq t<34,34 \leq t<41$ and $41 \leq t<48$. Note that, because of their different duration, the mass content of a perfectly conserved tracer differs for the different age classes. When a particle reaches 48 days of elapsed time, it is removed from the simulation; therefore even the conserved scalar (BCtr, see below) has a maximum time of residence in the atmosphere of 48 days. The model output is stored every 5 days as a 5-day average concentration $c(x, y, z, t)$ or, written in a discretized form, $c_{i j k, i t}$, where it is used as index for the age and $i, j, k$ are indices for the longitude, latitude and elevation above terrain level (ATL).

Aerosols are removed in FLEXPART by dry and wet deposition. The dry deposition is simulated according to a resistance approach (Wesely and Hicks, 1977) considering the aerodynamic resistance, the quasilaminar sublayer resistance, and gravitational settling (Slinn, 1982). For the aerosols considered in our simulations (see below), we assumed a logarithmic diameter distribution with a geometric mean diameter of $2.5 \times 10^{-7} \mathrm{~m}$, a geometric standard deviation of 1.25 , and a density of $1.4 \times 10^{3} \mathrm{~kg} \mathrm{~m}^{-3}$. Wet deposition distinguishes between in-cloud and below-cloud scavenging (McMahon and Denison, 1979; Hertel et al., 1995). Scavenging coefficients are determined primarily as a function of cloud liquid water content and precipitation rate, respectively. Note that FLEXPART has no aerosol processing scheme and that details such as the conversion of some aerosols from an initially hydrophobic to a hydrophilic state (Vignati et al., 2010) are ignored.

\subsection{Megacity emissions and deposition timescales}

The emission inventory is extracted from the original Representative Concentration Pathway (RCP) 8.5 emission scenario for the year 2005 developed by the MESSAGE (Model for Energy Supply Strategy Alternatives and their General Environmental impact) modeling team and IIASA (Integrated Assessment Framework at the International Institute for Applied Systems Analysis), Austria (see http://www. iiasa.ac.at and Riahi et al., 2007). The global emission data used here has a $1^{\circ} \times 1^{\circ}$ resolution and was obtained from the original data set at $0.5^{\circ} \times 0.5^{\circ}$. The mask used to identify the megacities' emissions was developed by Butler et al. (2009) and subsequently extended as reported in Folberth et al. (2012) to include extended agglomerations such as the Po Valley and other megacities, as agreed in the framework of the MEGAPOLI project. Any simulated megacity occupies one or more grid cells of this emission data set as listed in Table 1 and illustrated in Fig. 1 and, it is possible to see that both single-grid-cell as well as multiple-grid-cell megacities are included. From the RCP 8.5 data set, the emissions of several species can be extracted. It should be noted in Fig. 1 and in Table 1 that the definition of the megacities is not perfectly consistent since extended areas, like the agglomerate of New York, Boston and Washington (here just called the New York megacity for simplicity), the Dhaka megacity and the Po Valley are compared to more localized areas, like Chicago or Paris. However, the emission and population are consistently extracted using the same mask.

A first estimate on the relative importance of megacity emissions on a global scale can be deduced immediately from Fig. 2, where the cumulative emission contribution for several chemical species (black carbon, BC; carbon monoxide, $\mathrm{CO}$; nitrogen oxides, $\mathrm{NO}_{\mathrm{x}}$; sulfur dioxide, $\mathrm{SO}_{2}$ ) for all the megacities up to a given degree of latitude is scaled with the total cumulative species emission (including nonmegacity emission) to the same degree of latitude. For example the total cumulated emission starting from the South Pole and up to a specific latitude, $i_{\text {lat }}$, could be written as $\mathrm{CE}_{i_{\text {lat }}}=\sum_{j=-90}^{i_{\text {lat }}} \sum_{i=1}^{360} E(i, j)$, where $E(i, j)$ is the emission in grid cell $i, j$. Similarly, the cumulative contribution for all the cities starting from the South Pole to latitude $i_{\text {lat }}$ could be written as

$\mathrm{CEMC}_{i_{\text {lat }}}=\sum_{i_{\text {city }}=1}^{N_{\text {city }}} \sum_{i g=1}^{N_{\text {cells }}\left(i_{\text {city }}\right)} \sum_{j=-90}^{i_{\text {lat }}} \sum_{i=1}^{360} E(i, j) \delta\left(j-\operatorname{lat}\left(i_{\mathrm{g}}\right)\right) \delta\left(i-\operatorname{lon}\left(i_{\mathrm{g}}\right)\right),(1)$

where $N_{\text {city }}$ is the number of cities considered, $N_{\text {cells }}$ the number of cells representing the city and $\delta$ is a function with a value of one within the city limits and zero outside.

The data have been separated in the Northern and Southern Hemisphere (NH and $\mathrm{SH}$ ), and the cumulative contribution 
Table 1. Several quantities for all the megacities being part of this study are reported. $T_{\mathrm{li}}$ and $T_{\mathrm{lo}}$ are two decaying timescales obtained for the deposition process (see Fig. 3 and the text for details). PWC is the population-weighted ground level concentration and measures the concentration to which the population inside the city is exposed on average. GLC $\times$ Pop is the product of population and ground level concentration. Other quantities are self explanatory.

\begin{tabular}{|c|c|c|c|c|c|c|c|c|c|}
\hline \multirow{3}{*}{$\begin{array}{l}\text { Properties } \\
\text { City name (short name) }\end{array}$} & \multirow[t]{3}{*}{ N. cells } & \multirow{3}{*}{$\begin{array}{l}\begin{array}{l}\text { City } \\
\text { popula- } \\
\text { tion }\end{array} \\
10^{6} \times \\
\text { people }\end{array}$} & \multirow{3}{*}{$\begin{array}{l}\text { Emission } \\
10^{6} \mathrm{~kg}^{-1} \\
\times \mathrm{Yr}^{-1}\end{array}$} & \multirow{3}{*}{$\begin{array}{l}T_{\mathrm{lo}} \\
\text { BCdp } \\
\text { days }\end{array}$} & \multirow{3}{*}{$\begin{array}{l}T_{\mathrm{li}} \\
\text { BCdp } \\
\text { days }\end{array}$} & \multirow{3}{*}{$\begin{array}{l}\text { PWC } \\
\text { BCdp } \\
\mathrm{ng} \mathrm{m}^{-3}\end{array}$} & \multirow{3}{*}{$\begin{array}{l}\text { PWC } \\
\text { BCtr } \\
\mathrm{ng} \mathrm{m}^{-3}\end{array}$} & \multicolumn{2}{|c|}{ GLC. $\times$ Pop. } \\
\hline & & & & & & & & \multicolumn{2}{|c|}{$10^{10} \mathrm{ng} \mathrm{m}^{-3} \times$ people } \\
\hline & & & & & & & & $\mathrm{BCtr}$ & BCdp \\
\hline \multicolumn{10}{|l|}{ Europe } \\
\hline Istanbul (ISTANB) & 4 & 13.9 & 2.17 & 7.8 & 5.0 & 61 & 64 & 2.4 & 1.2 \\
\hline London(LONDON) & 2 & 14.2 & 5.85 & 5.7 & 1.5 & 379 & 398 & 10 & 6.8 \\
\hline Moscow(MOSCOW) & 1 & 14.6 & 6.74 & 5.7 & 2.4 & 884 & 931 & 19 & 14 \\
\hline Paris(PARIS) & 1 & 9.9 & 5.06 & 6.3 & 1.8 & 543 & 563 & 10 & 6.7 \\
\hline Po Valley(POVALL) & 11 & 22.7 & 14.8 & 7.6 & 3.7 & 282 & 335 & 17 & 8.8 \\
\hline Ruhr Valley(RUHRVA) & 3 & 13.6 & 7.98 & 6.0 & 1.7 & 362 & 388 & 14 & 8.1 \\
\hline St. Petersburg(STPBRG) & 2 & 2.6 & 3.42 & 5.5 & 1.4 & 235 & 234 & 3 & 0.9 \\
\hline \multicolumn{10}{|l|}{ North America } \\
\hline Chicago(CHICAG) & 1 & 5.5 & 2.42 & 5.9 & 2.1 & 227 & 236 & 2.9 & 1.7 \\
\hline Los Angeles(LOSANG) & 4 & 17.2 & 12.7 & 7.9 & 6.0 & 583 & 606 & 15 & 11 \\
\hline New York(NEWYOR) & 15 & 45.5 & 38.0 & 5.7 & 1.7 & 454 & 518 & 40 & 22 \\
\hline \multicolumn{10}{|l|}{ Mexico \& South America } \\
\hline Buenos Aires(BAIRES) & 1 & 13.0 & 5.07 & 5.9 & 2.4 & 556 & 582 & 8.4 & 7.6 \\
\hline Lima(LIMA) & 4 & 8.1 & 5.22 & 7.4 & 6.0 & 164 & 181 & 2.4 & 1.6 \\
\hline Mexico City(MEXICO) & 2 & 25.2 & 8.03 & 7.8 & 5.9 & 340 & 360 & 12 & 9.4 \\
\hline Rio de Janeiro(RIODEJ) & 1 & 10.7 & 5.00 & 6.3 & 1.7 & 368 & 429 & 6 & 4.4 \\
\hline Sao Paulo(SAPAUL) & 1 & 21.2 & 8.55 & 6.1 & 1.9 & 548 & 623 & 15 & 12 \\
\hline Santiago(SNTAGO) & 1 & 6.0 & 5.53 & 6.9 & 5.3 & 512 & 520 & 3.9 & 3.3 \\
\hline \multicolumn{10}{|l|}{ Asia } \\
\hline Bangkok(BANGKO) & 1 & 11.4 & 7.01 & 6.7 & 2.2 & 593 & 633 & 11 & 7.8 \\
\hline Beijing(BEIJIN) & 1 & 9.7 & 12.1 & 6.2 & 3.5 & 1273 & 1315 & 37 & 27 \\
\hline Delhi(DELHI) & 1 & 25.5 & 8.41 & 8.5 & 6.1 & 1184 & 1228 & 61 & 53 \\
\hline Dhaka(DHAKA) & 11 & 138 & 32.5 & 7.1 & 2.4 & 637 & 753 & 149 & 104 \\
\hline Hong Kong(HONKON) & 4 & 51.7 & 44.2 & 6.0 & 1.7 & 1109 & 1281 & 105 & 69 \\
\hline Jakarta(JAKART) & 1 & 25.7 & 10.4 & 6.6 & 1.0 & 802 & 968 & 31 & 23 \\
\hline Karachi(KARACH) & 1 & 9.3 & 1.91 & 8.9 & 8.2 & 137 & 138 & 3.5 & 2.5 \\
\hline Kolkata(KOLKAT) & 1 & 28.1 & 7.66 & 7.3 & 2.8 & 901 & 949 & 42 & 32 \\
\hline Manila(MANILA) & 2 & 22.5 & 7.65 & 6.8 & 1.2 & 220 & 265 & 8.6 & 5.3 \\
\hline Mumbai(MUMBAI) & 4 & 30.0 & 12.9 & 8.6 & 5.2 & 312 & 333 & 21 & 13 \\
\hline Osaka(OSAKA) & 1 & 16.0 & 8.32 & 5.9 & 1.8 & 534 & 572 & 13 & 9.8 \\
\hline Seoul(SEOUL) & 2 & 23.8 & 25.9 & 5.9 & 2.6 & 1535 & 1621 & 60 & 44 \\
\hline Shanghai(SHANGH) & 1 & 18.1 & 7.87 & 6.1 & 2.2 & 626 & 657 & 26 & 18 \\
\hline Teheran(TEHERA) & 1 & 11.5 & 3.51 & 8.4 & 8.2 & 349 & 358 & 6.7 & 5 \\
\hline Tianjin(TIAAJI) & 1 & 8.9 & 7.67 & 6.2 & 3.4 & 855 & 882 & 23 & 16 \\
\hline Tokyo(TOKYO) & 1 & 28.7 & 15.3 & 5.8 & 1.6 & 1206 & 1306 & 46 & 37 \\
\hline \multicolumn{10}{|l|}{ Africa } \\
\hline Cairo(CAIRO) & 1 & 22.3 & 5.59 & 9.6 & 10.5 & 472 & 473 & 15 & 13 \\
\hline Johannesburg(JOBURG) & 2 & 7.6 & 11.4 & 7.4 & 5.3 & 759 & 778 & 8.3 & 7 \\
\hline Lagos(LAGOS) & 1 & 9.7 & 2.84 & 7.5 & 3.4 & 220 & 261 & 4.9 & 2.9 \\
\hline \multicolumn{10}{|l|}{ Australia } \\
\hline Sydney(SYDNEY) & 5 & 5.1 & 7.44 & 6.8 & 3.0 & 145 & 158 & 1.2 & 0.8 \\
\hline Averaged value & & 20.8 & 10.5 & 6.86 & 3.52 & 565 & 608 & 23.7 & 17.4 \\
\hline
\end{tabular}




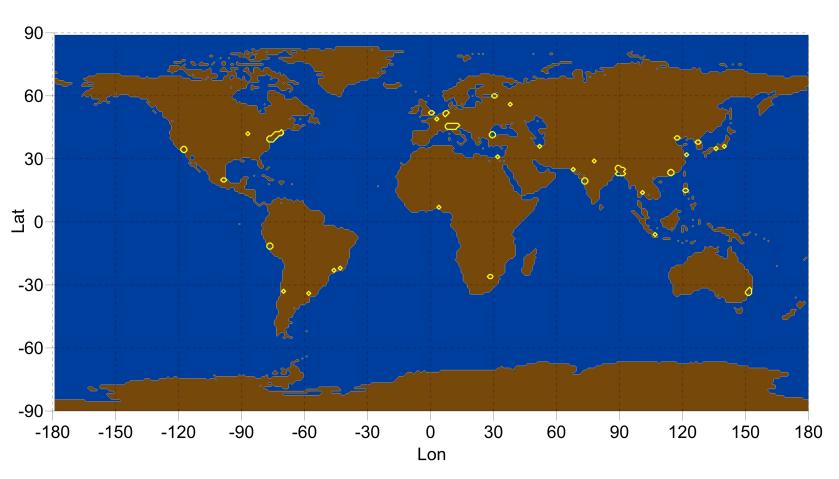

Fig. 1. Location and extension of the megacities investigated.

is calculated starting from the North and the South Pole, respectively. No data are shown south of $35^{\circ} \mathrm{S}$ and north of $60^{\circ} \mathrm{N}$ since there are no megacities. Further, the data are separated into autumn/winter emissions and spring/summer emissions. It can be seen that the $35^{\circ} \mathrm{S}$ latitude megacities in the SH contribute more to total emissions than their counterparts in the $\mathrm{NH}$. In the $\mathrm{NH}$, there is a strong seasonal variation at higher latitudes especially for $\mathrm{CO}$ and $\mathrm{BC}$, which is due to intense open biomass burning in spring and summer, so that megacity emissions contribute less in summer. In the autumn and winter months, a single city (St. Petersburg) accounts for almost $10 \%$ of the total emissions north of about $60^{\circ} \mathrm{N}$ for the $\mathrm{BC}$ considered in this study. It can be of interest to note that, adding to the list of cities an emitting area extending from a lower left corner of $\left(59^{\circ} \mathrm{N}, 10^{\circ} \mathrm{E}\right)$ to an upper right corner $\left(61^{\circ} \mathrm{N}, 26^{\circ} \mathrm{E}\right)$, the emission fraction goes up to $36 \%$ of the total emission over $60^{\circ} \mathrm{N}$ for $\mathrm{BC}$ in autumn and winter. This area contains five large urban areas in the Baltic and Scandinavian countries: Tallinn (Estonia), Helsinki (Finland), Stockholm and Uppsala (Sweden), and Oslo (Norway). Since on the scale of this study these cities are relatively close to the investigated megacity of St. Petersburg, the results obtained for this latter city could be of guidance for the behavior of emissions that in the autumn and winter contribute $36 \%$ of the total world emissions north of $60^{\circ} \mathrm{N}$. These cities' contribution is lower in the summer, but considering that during these months the concentrations of $\mathrm{BC}$ in the Arctic lower atmosphere are lower due to stronger deposition processes (e.g., Hirdman et al., 2010), the winter peak of these urban emissions could be significant. However, it is important to mention here that emissions from individual cities can differ, often by a factor of two, between different emission inventories (Butler et al., 2008) and this uncertainty is implicitly contained in our analysis.

The further discussion in this paper will be based only on the emissions of one species, $\mathrm{BC}$, which we consider as representative for all combustion-related emissions. This species will be used for two different artificial scalar tracers: one considered as a conserved tracer (BCtr) and not subject to any

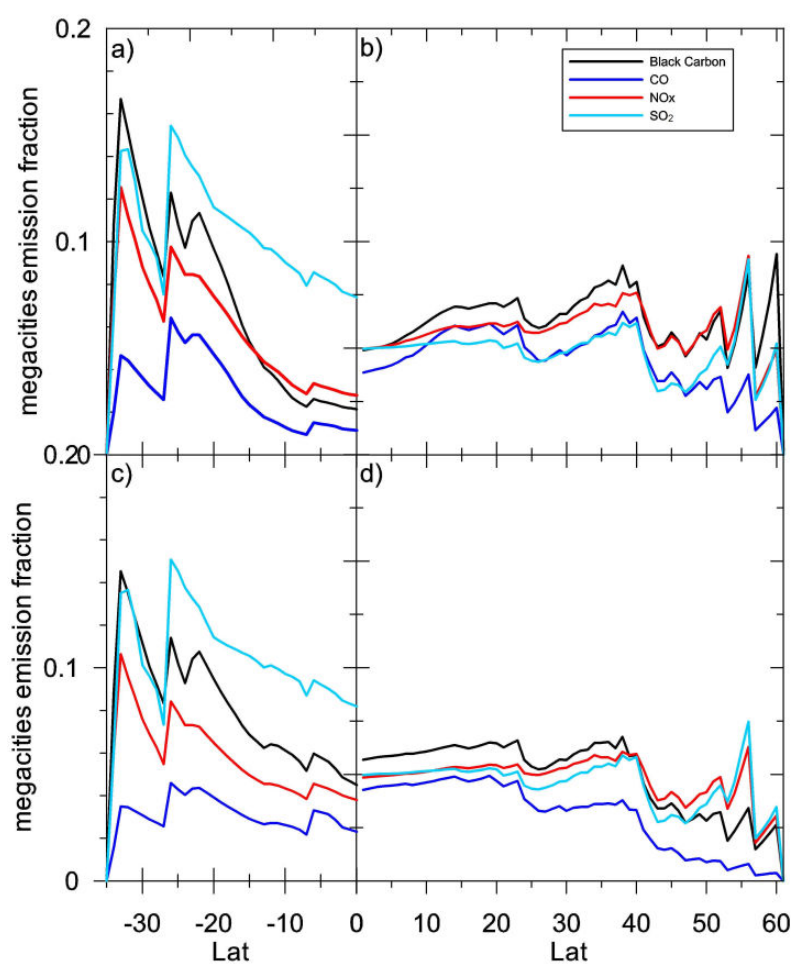

Fig. 2. Relative contribution of the megacity emissions for $\mathrm{BC}$, carbon monoxide $(\mathrm{CO})$, nitrogen oxides $\left(\mathrm{NO}_{\mathrm{X}}\right)$ and sulfur dioxide $\left(\mathrm{SO}_{2}\right)$ accumulated from the poles towards the equator, relative to the accumulated global emission as a function of the latitude south of the North Pole $(\mathbf{b}, \mathbf{d})$ and north of the South Pole (a, c) and divided as winter $(\mathbf{a}, \mathbf{b})$ and summer $(\mathbf{c}, \mathbf{d})$.

removal process and another one (BCdp) with dry and wet deposition processes included in the simulations.

For studying the impact of pollution on human population we used the GPWv3 data set of the Center for International Earth Science Information Network (CIESIN), Columbia University - available at http://sedac.ciesin.columbia.edu/ gpw (January 2011). The population of a city was extracted from the GPWv3 data set, using the same megacity mask used for the emission; the resulting population for the cities is listed in Table 1.

Before proceeding with a detailed analysis of the plume characteristics it is useful to explore the effects of the modeled wet and dry deposition processes on the suspended mass in the atmosphere as a function of time after emission ("age"). The deposition processes reduce the mass content significantly with age but differently for the different cities considered. In most figures in this paper, megacities have been divided into $\mathrm{NH}$ and $\mathrm{SH}$ megacities, and the results of these two groups will be in general plotted separately to improve the clarity and readability of the figures.

Figure $3 \mathrm{a}$ and $\mathrm{b}$ show the three-year averaged mass content (mid-December 2002 to mid-December 2005; see Sect. 3) of $\mathrm{BCdp}$ normalized for that of $\mathrm{BCtr}$ in any age class on 


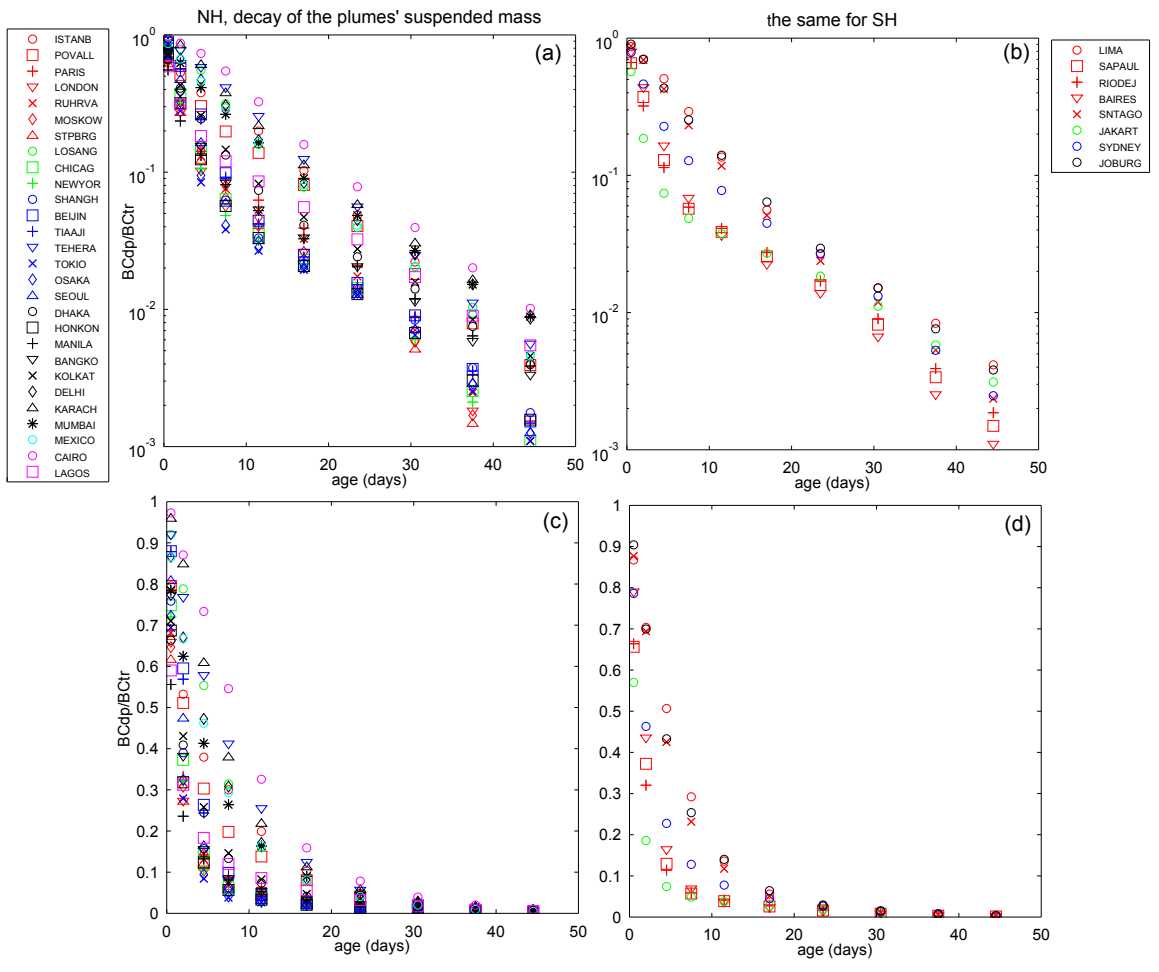

Fig. 3. Total mass of BCdp normalized with that of BCtr (BCdp/BCtr) as function of the age for the Northern Hemisphere (NH, a) and the Southern Hemisphere ( $\mathrm{SH}, \mathbf{b})$. Lower panels $(\mathbf{c}, \mathbf{d})$ as above but using a linear scale.

a logarithmic scale, while Fig. 3c, d shows the same ratio on a linear scale. This indicates how dry and wet deposition processes deplete the atmospheric mass of BCdp with time. From Fig. 3c, d it is apparent that, initially, deposition processes are more active for European and tropical cities. However, after a few days the plumes originating from megacities located at midlatitudes in Asia are those characterized by the higher deposition rates, related to strong scavenging in the North Pacific storm track (Fig. 3a, b). For the last few age classes, European and North American plumes have again higher deposition rates. This complex behavior reflects the different three-dimensional distributions of the plumes originating from different geographical regions. For very large ages, all the plumes should converge towards the same deposition rates typical of the Northern and Southern Hemisphere, while initially the deposition rate is strongly influenced by the local processes close to the source. This can be better appreciated defining two timescales obtained by fitting an exponential decay to the data on a logarithmic scale, $T_{\mathrm{lo}}$, (based on Fig. 3a, b) and to the data on a linear scale, $T_{\text {li }}$ (based on Fig. 3c, d). These timescales are reported in Table $1 . T_{\mathrm{lo}}$ is an estimate of the average e-folding deposition timescale for the 48-day time window and the source location. $T_{\mathrm{li}}$ being more related to the initially higher values of $\mathrm{BCdp} / \mathrm{BCtr}$, gives an idea about the time needed for the mass emitted from a specific source to be depleted to a small fraction of its initial value, and therefore it should strongly depend on the local processes in the boundary layer close to the source. $T_{\text {li }}$ varies between one and ten days, while $T_{\mathrm{lo}}$ varies between about six and nine days, but with most of the cases between about six and eight days, indicating the approximate averaged global e-folding lifetime of the BCdp aerosols in FLEXPART.

An important feature of including age classes in the analysis is that many of the results reported here involving a mass assigned to the age classes can be extended to consider the effect of a superimposed decay process (e.g., radioactive decay, or chemical destruction) just by applying, a posteriori, the decay - e.g., exponential characterized by an assigned timescale. This is true for both BCtr and BCdp. In the first case the superimposed decay is applied to a substance not undergoing deposition, and in the second case to a substance undergoing wet and dry deposition.

\section{Dispersion characteristics of transported plume}

In this section we start the discussion about the megacity plumes with an analysis of their physical dispersion characteristics both horizontally and vertically. To characterize the horizontal dispersion of the plumes, the model output was first averaged over the time period of interest (e.g., three winter seasons or all three years): 

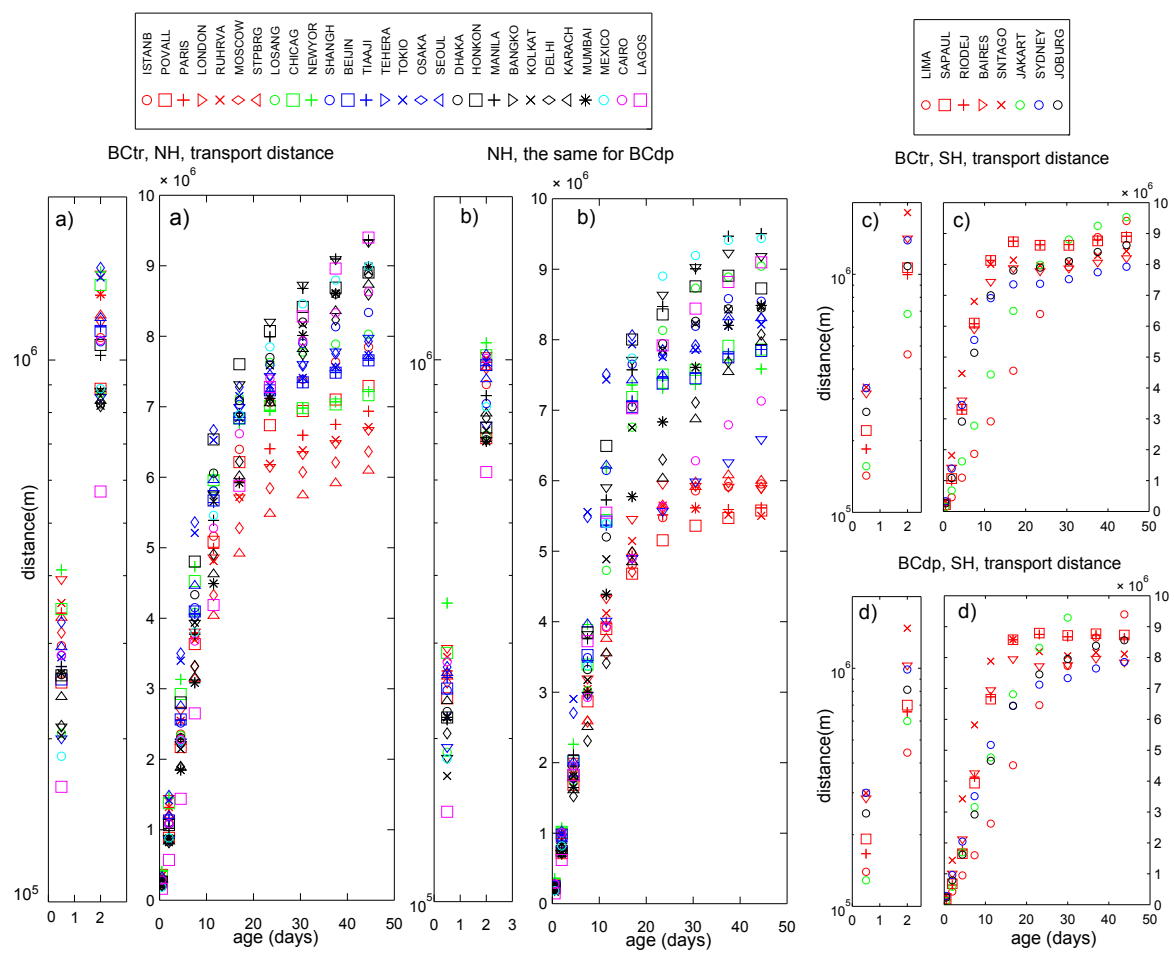

Fig. 4. Transport distance $(\bar{d}(t))$ from the source megacity location for the vertically integrated concentration of BCtr and BCdp for the NH (a, b) and SH (c, d). The smaller panels on the left are a zoom for 0-3 days using a logarithmic scale.

$\tilde{c}(x, y, z, t)=\frac{1}{N} \sum_{i=1}^{N} c_{i}(x, y, z, t)$

Here $N$ indicates the number of 5-day output intervals in the period of interest, $x, y, z$ are the three space dimensions, and $t$ indicates the elapsed time from the release (i.e., the age). From this time-averaged concentration a vertically integrated concentration field was introduced:

$\tilde{c}_{z}(x, y, t)=\sum_{k=1}^{N_{z}} \tilde{c}\left(x, y, z_{k}, t\right) \Delta z_{k}$.

Here $\Delta z_{k}$ indicates the vertical grid level extension and $N_{z}$ $(=25)$ is the number of vertical levels in the FLEXPART output grid. From this field an advection measure was obtained as the average distance of the mass from the source location, $\bar{d}(t)$, in the following called transport distance,

$\bar{d}(t)=\frac{\sum_{i=1}^{360} \sum_{j=1}^{180} d_{i j}\left(\tilde{c}_{z}(t)\right)_{i j} \Delta_{i j}}{\sum_{i=1}^{360} \sum_{j=1}^{180}\left(\tilde{c}_{z}(t)\right)_{i j} \Delta_{i j}}$,

where $d_{i j}$ is used to indicate the distance, along the Earth's surface, between the center of the grid point with indices $(i, j)$ and the source position. Since some sources are composed of more than one single grid cell element, the source position was defined as the grid element containing the maximum ground level concentration averaged over the extension of the first age class (i.e., $0<t<1$ day). $\Delta_{i j}$ is the area of a grid element with indices $(i, j)$, and $\left(\tilde{c}_{z}\right)_{i j}$ is the concentration associated with the grid element. It should be noted again that, since the grid extends also in the time dimension, any of these measures is defined as a function of age for the intervals defined above. In a similar manner, the averaged vertical position, $\bar{h}(t)$, of the horizontally integrated concentration $\left(\tilde{c}_{x y}\right)_{k}$ as a function of time can be introduced, where $k$ is used for the vertical grid cell index.

The results for the distance from the source location, $\bar{d}(t)$, for BCtr are shown in Fig. 4a and c, respectively, for the $\mathrm{NH}$ and the $\mathrm{SH}$, and those for BCdp are shown in Fig. $4 \mathrm{~b}$ and d. The smaller left panels are a zoom into the age classes 0-1 and 1-3 days and use a logarithmic scale for the plot. For BCtr in the $\mathrm{NH}$, it can be seen that initially the plumes subject to the fastest advection are those emitted at higher latitude and associated therefore with European and North American megacities, while the plumes emitted by tropical or subtropical megacities have the slowest initial transport. However, the situation changes, and for elapsed time greater than 10 days all the higher latitude cities show comparatively short transport distances. Conversely, the tropical and subtropical megacity plumes then become associated with the 


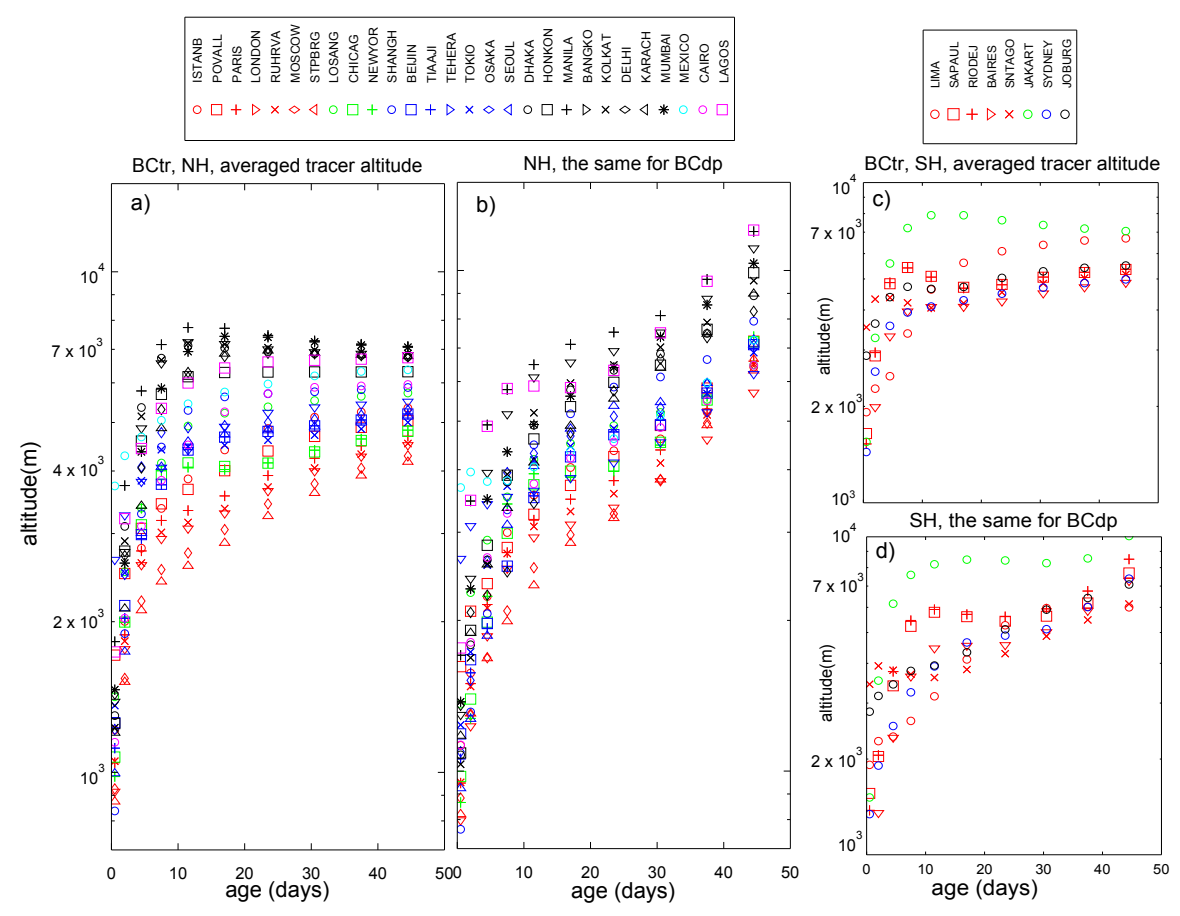

Fig. 5. Altitude (above sea level) of the center of mass of horizontally integrated concentration $(\bar{h}(t))$ for BCtr $(\mathbf{a}, \mathbf{c})$ and $\mathrm{BCdp}(\mathbf{b}, \mathbf{d})$ in the $\mathrm{NH}(\mathbf{a}, \mathbf{b})$ and in the $\mathrm{SH}(\mathbf{c}, \mathbf{d})$.

largest transport distances. Asian megacities of intermediate latitude (blue symbols) have in general intermediate characteristics. The reason for this latitude-dependent behavior is influenced by three factors: (1) the plumes are transported preferentially zonally before spreading meridionally due to latitudinal transport barriers, and the length of a circle of latitude is largest at the equator; (2) cities at lower latitudes have a larger possible asymptotic distance for a uniform scalar distribution in the hemisphere; and (3) the tropics are characterized by lower near-surface wind speeds but a high frequency of deep convection, so that the dispersion is at first slower than for higher-latitude cities but after a few days significant amounts of tracer in the tropics are transported by deep convection to the upper troposphere, where winds are faster. This is illustrated in Fig. 5a and c, which shows that tropical cities and particularly southeast Asian cities (e.g., Manila) are associated with a very fast increase of the plume average elevation.

The zoom figures for the horizontal transport behavior between 1 and 3 days (Fig. 4) show that in the NH the cities with the initial fastest plume transport are London, New York, Osaka and Tokyo. These are all cities close to the ocean which is therefore an important factor in determining a fast early phase of plume transport. Among the European megacities the Po Valley shows a unique behavior since the tracer is trapped there by mountains on three sides, which strongly limits the early phase of transport. One consequence of this is the high pollution levels usually registered in this area (e.g.,
Bigi et al., 2012). However, overall in the NH the megacity with the slowest horizontal transport up to 10 days is the tropical city of Lagos, which also has severe air pollution problems (Baumbach et al., 1995).

Removal processes lead to a reduction of BCdp mass in the atmosphere. The lifetime $T_{\mathrm{li}}$ of the BCdp tracer for the various megacities ranges from 1.0 days for Jakarta to 10.5 days for Cairo (Table 1), reflecting the very different efficiencies of wet scavenging in tropical and desert regions. This large difference in the scavenging has also been reported and quantified, based on climate classes, in Kunkel et al. (2012): for small aerosol particles, a large remote deposition fraction over $1000 \mathrm{~km}$ was found for cities located in arid regions (average of about $75 \%$ ), while a much lower value (36\%) was found for cities in tropical regions.

Removal processes also change the transport characteristics of the BCdp plumes, and these changes are sometimes difficult to understand (Fig. 4b, d). For example, the preferential removal of mass during upward transport associated with precipitation means that initially the vertical transport of BCdp is slower compared to BCtr (Fig. 5). As a consequence, initially the horizontal transport is dominated by the slower low-level winds, leading also to shorter horizontal transport distances of BCdp compared to BCtr (see left panels in Fig. 4). After a few days, however, due to preferential wet scavenging in the lower troposphere versus lack of precipitation in the upper troposphere and lower stratosphere, for the remaining BCdp the fraction located in the 

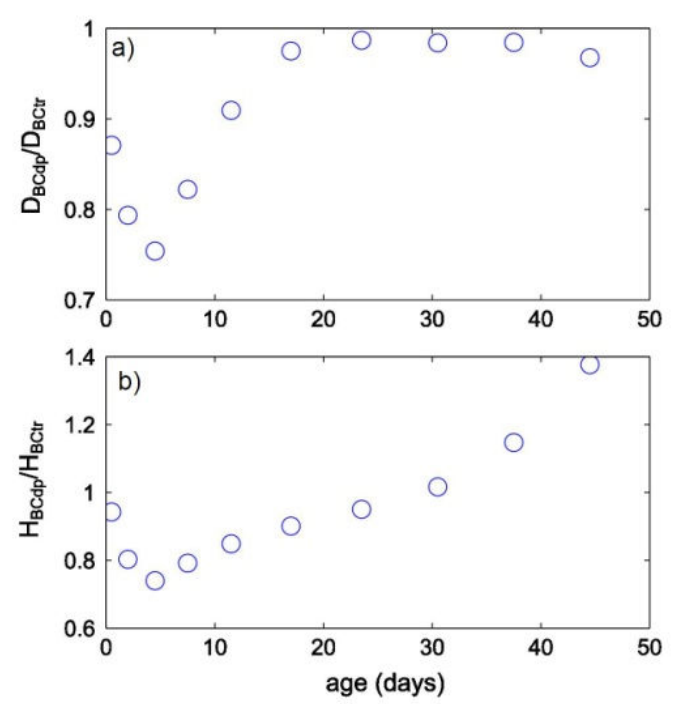

Fig. 6. Ratio of the averaged (over all cities) horizontal distance of centers of mass, $D(t)$, and vertical position of center of mass, $H(t)$, for BCdp over BCtr.

upper troposphere and stratosphere increases. Thus, the centroid altitude of the BCdp tracer increases throughout all remaining age classes (Fig. 5b, d), and the horizontal transport distance also catches up with that of BCtr (Fig. 4b). This is summarized in Fig. 6a and b, which shows the ratio, for BCdp versus BCtr, of the horizontal transport distances $\left(D(t)=\sum_{i=1}^{N_{\text {cities }}} \bar{d}_{i}(t) / N_{\text {cities }}\right)$ and of the average megacities plume altitude $\left(H(t)=\sum_{i=1}^{N_{\text {cities }}} \overline{h_{i}}(t) / N_{\text {cities }}\right)$ for all cities. Notice that these results for $H(t)$ do not imply that a larger fraction of the total emissions can reach the upper troposphere for BCdp than for BCtr. However, after some time a larger relative fraction of the remaining BCdp than of the remaining $\mathrm{BCtr}$ resides in the upper troposphere, as demonstrated in Fig. 7, which shows the fraction of the total BCtr and BCdp mass suspended in the atmosphere which is contained between $9 \mathrm{~km}$ and the top of our sampling domain $(30 \mathrm{~km})$. For BCdp, this fraction increases throughout the 48 days considered in our study, and for some cities it approaches the value of 1 (Fig. $7 \mathrm{~b}$ and d).

The SH megacity plumes have a similar behavior compared to their NH counterparts. Midlatitude megacity plumes show initially a faster horizontal transport, while ultimately the tropical and subtropical latitude megacity plume have a larger transport distance. However, the transport for midlatitude cities is here faster than in the $\mathrm{NH}$, and the plumes reach faster their temporary asymptotic distance. In fact Fig. 4c shows that for BCtr all the plumes but the Lima and Jakarta plumes are transported more rapidly compared to the $\mathrm{NH}$ plumes. This behavior is likely related to the stronger west- erlies in the SH. Jakarta shows a typical behavior of a tropical megacity as previously discussed for the $\mathrm{NH}$, while Lima shows the slowest horizontal transport speed of all the megacity plumes investigated.

\section{Statistical measures of regional pollution export}

L07 defined several metrics to characterize the dispersion of the megacity plumes and their potential impact on a regional scale. Here we will calculate within our modeling framework two of their metrics of pollutant export over long range (ELRcol and ELR $1 \mathrm{~km}$ ) and compare our results with theirs. ELRcol is defined as the fraction of the total BC mass in the atmosphere which is more than $1000 \mathrm{~km}$ away from the source at any altitude. ELR $1 \mathrm{~km}$ is the same as ELRcol but for the mass contained in the first $1 \mathrm{~km}$ ATL. Contrary to L07 we considered only whole grid cells and did not split grid cells according to their fractions within or beyond the $1000 \mathrm{~km}$ radius from the source; however, our grid has finer resolution $\left(1^{\circ}\right.$ versus $\left.1.9^{\circ}\right)$, which compensates for this less accurate treatment. Also, the simulations of L07 were for the year 1995, while our simulations are for the years 2003-2005. Also, as before, we will investigate the effect of the deposition, thus extending the results of L07.

Our age class treatment generalizes these metrics to any decay time within the 48-day range considered. The ELR measure has been calculated as cumulated mass exported up to a specific age normalized with the total mass of the substance suspended in the atmosphere cumulated up to the same age. This means that the value of the last age class corresponds to the total exported mass fraction.

L07 report in detail the ELR1 $\mathrm{km}$ values for a scalar with a 10-day decaying timescale. Figure 8 a shows that the value of ELR $1 \mathrm{~km}$ for BCtr becomes, after about one week, almost constant for most cities. This means that all tracers with a decay timescale larger than about one week will behave similarly to a purely passive tracer without decay. This simply reflects the partitioning of the tracer between the lowest $1 \mathrm{~km}$ and the rest of the atmosphere, as basically all of the tracer will be exported beyond $1000 \mathrm{~km}$ after a week. However, using the discretized time dependence information present in the age class partitioning we can explicitly apply the exact exponential decay process with a 10-day timescale to allow a more precise comparison of our results to those of L07. Table 2 compares the ELR $1 \mathrm{~km}$ results for the 48-day age class for a conserved tracer with those for a tracer with a 10-day lifetime (BC10). The results of $\mathrm{L} 07$ for BC10 are also reported. It is possible to see that the difference between $\mathrm{BC} 10$ and the conserved tracer, $\mathrm{BCtr}$, is minor in most of the cases. However, in general and as expected, the results obtained for the decaying scalar agree better with the results reported by L07. Considering that the results of L07 were for a different year and used different meteorological input data (NCEP reanalysis) and a different transport model (MATCH), the 


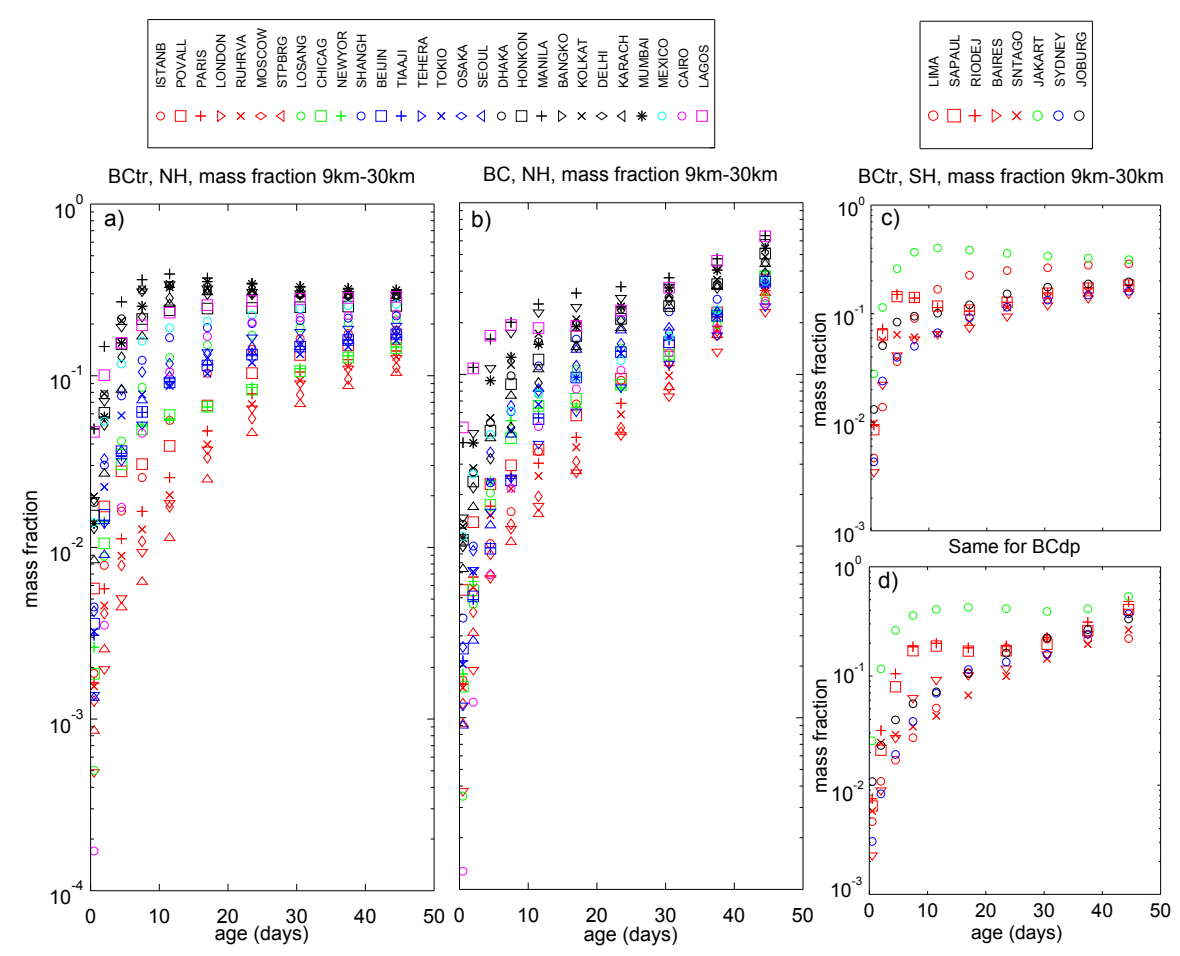

Fig. 7. Mass in the upper troposphere and stratosphere $(9-30 \mathrm{~km})$ normalized by the total mass suspended in the atmosphere as a function of tracer age for BCtr and BCdp, for the $\mathrm{NH}(\mathbf{a}, \mathbf{b})$ and $\mathrm{SH}(\mathbf{c}, \mathbf{d})$.

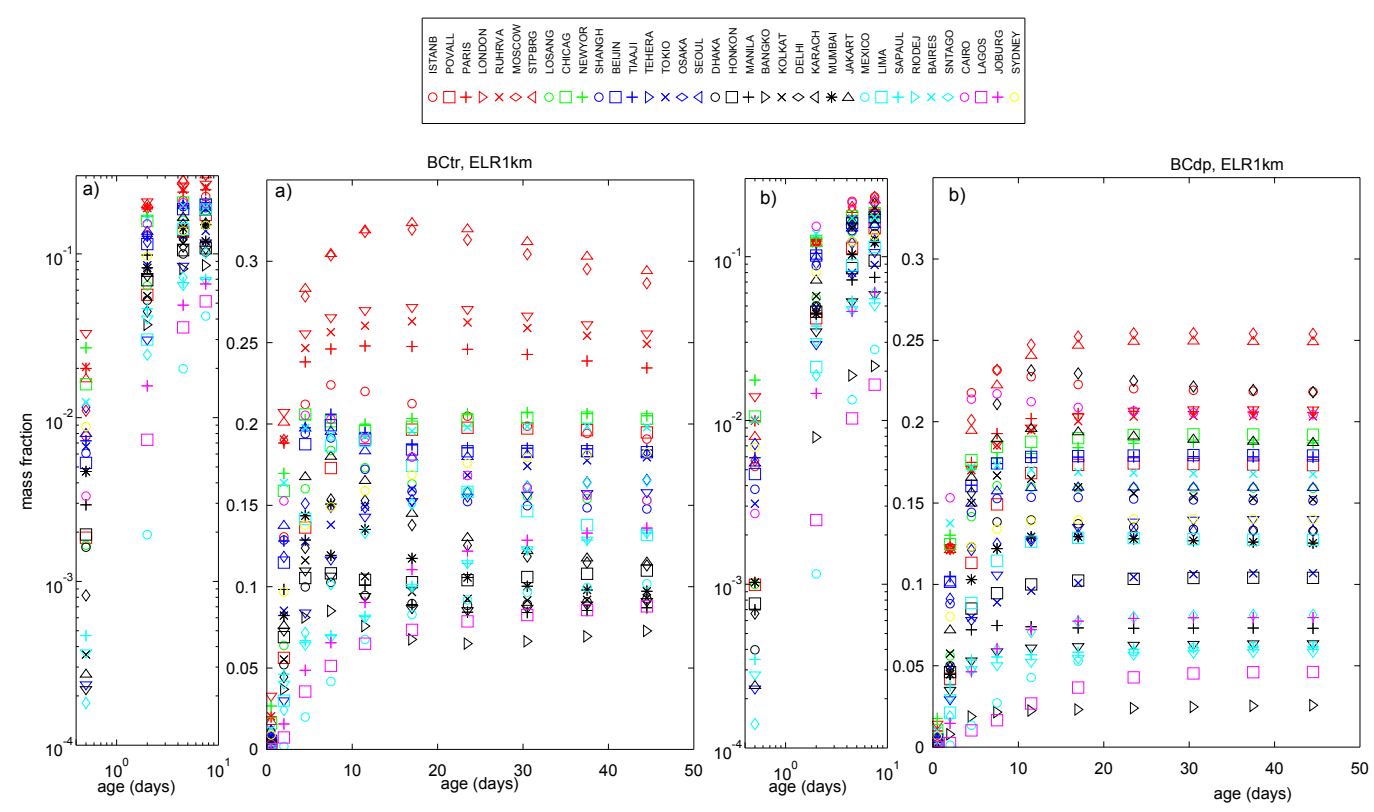

Fig. 8. Fraction of BCtr (a) and BCdp (b) mass exported over $1000 \mathrm{~km}$ but with elevation below $1 \mathrm{~km}$ above ground level: ELR1 km. The fraction is calculated as cumulated mass exported up to a specific age normalized with the total suspended mass in the atmosphere up to this age. 


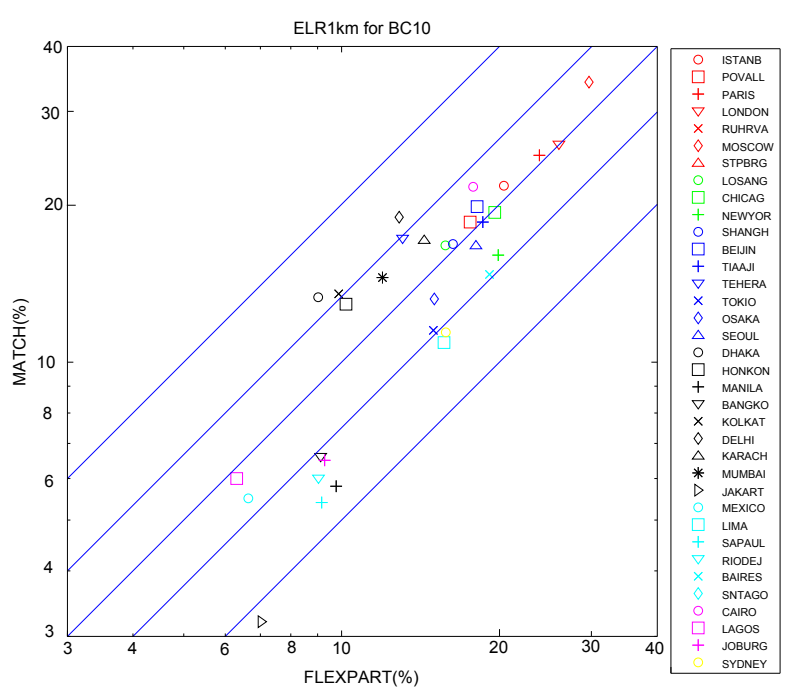

Fig. 9. Scatter plot of ELR $1 \mathrm{~km}$ for the values of BC10 reported in Table 2, produced by FLEXPART for the years 2003-2005 and MATCH for the year 1995.

agreement between the two studies is very good. The values of ELR $1 \mathrm{~km}$ obtained in our study range from $6.3 \%$ to $30.1 \%$ compared with $3.2 \%$ to $34 \%$ in L07.

A scatter plot (Fig. 9) shows that the ELR1km values for European, North American and midlatitude Asian cities agree reasonably well in the two studies. Southern Hemisphere megacities have generally higher values in the present calculation based on FLEXPART. The worst agreement is achieved for the Indian subcontinent, Asian tropical and South American megacities, although the differences are not systematic. Jakarta stands out with ELR1 km values of $7 \%$ and $3.2 \%$ in FLEXPART and MATCH, respectively. This difference must be related to the different convection schemes used in FLEXPART (Emanuel and ZivcovicRothman scheme, implemented by Forster et al., 2007) and MATCH (plume ensemble scheme, proposed by Lawrence and Rasch, 2005). The low fraction in MATCH means that in this model the BC10 tracer must have been vented out of the boundary layer very efficiently, with only small compensating downward fluxes. This result is obtained, in somewhat less extreme form, also for other tropical cities such as Manila, Bangkok, Sao Paulo and Rio de Janeiro. On the other hand, FLEXPART has lower ELR1 $\mathrm{km}$ values than MATCH for the cities on the Indian subcontinent. This is probably due to different representation of the winter monsoon in the two models, where FLEXPART shows a relatively rapid lowlevel southward transport to the intertropical convergence zone, followed by rapid lifting (Stohl et al., 2002).

Figure $8 \mathrm{~b}$ shows the metric ELR $1 \mathrm{~km}$ computed for BCdp. The export efficiency for the BCdp tracer depends not only on the combined action of horizontal wind and vertical transport, but also on the removal by wet and dry deposition.
Table 2. Comparison of ELR $1 \mathrm{~km}$ for a conserved tracer with no decay (BCtr) and one subject to deposition (BCdp), for the BCtr tracer with a superimposed exponential decay process with a timescale of 10 days (BC10, see text for clarification) and a tracer with a 10-day decay timescale computed by L07 using the model MATCH for the year 1995 .

\begin{tabular}{|c|c|c|c|c|}
\hline $\begin{array}{ll} & \text { ELR1km }(\%) \\
\text { Cities } & \end{array}$ & $\mathrm{BCtr}$ & BCdp & $\begin{array}{l}\text { BC10 } \\
\text { FLEX }\end{array}$ & $\begin{array}{l}\text { BC10 } \\
\text { MATCH }\end{array}$ \\
\hline \multicolumn{5}{|l|}{ Europe } \\
\hline ISTANB & 19.1 & 21.8 & 20.4 & 21.7 \\
\hline LONDON & 25.5 & 20.7 & 25.9 & 26.0 \\
\hline MOSCOW & 28.6 & 25.4 & 29.6 & 34.2 \\
\hline PARIS & 23.4 & 20.6 & 23.8 & 24.8 \\
\hline POVALL & 19.5 & 17.3 & 17.6 & 18.5 \\
\hline RUHRVA & 24.9 & 20.3 & 25.1 & - \\
\hline STPBRG & 29.3 & 24.9 & 30.1 & - \\
\hline \multicolumn{5}{|l|}{ North America } \\
\hline CHICAG & 20.3 & 19.2 & 19.6 & 19.3 \\
\hline LOSANG & 15.3 & 15.9 & 15.8 & 16.7 \\
\hline NEWYORK & 20.5 & 18.7 & 19.9 & 16.0 \\
\hline \multicolumn{5}{|l|}{ Mexico \& South America } \\
\hline BAIRES & 19.8 & 16.8 & 19.1 & 14.7 \\
\hline LIMA & 13.1 & 12.7 & 15.7 & 10.9 \\
\hline MEXICO & 10.1 & 6.2 & 6.6 & 5.5 \\
\hline RIODEJ & 13.2 & 5.8 & 9.0 & 6.0 \\
\hline SAPAUL & 13.3 & 6.2 & 9.2 & 5.4 \\
\hline SNTAGO & 16.5 & 8.1 & 12.7 & - \\
\hline \multicolumn{5}{|l|}{ Asia } \\
\hline BANGKO & 9.1 & 6.3 & 9.1 & 6.6 \\
\hline BEIJIN & 18.3 & 17.9 & 18.1 & 19.8 \\
\hline DELHII & 11.3 & 21.8 & 12.9 & 18.9 \\
\hline DHAKA & 9.2 & 13.3 & 9.0 & 13.3 \\
\hline HONKON & 10.9 & 10.4 & 10.1 & 12.9 \\
\hline JAKART & 7.3 & 2.6 & 7.0 & 3.2 \\
\hline KARACH & 11.5 & 18.7 & 14.4 & 17.1 \\
\hline KOLKAT & 9.3 & 15.2 & 9.8 & 13.5 \\
\hline MANILA & 8.7 & 7.3 & 9.8 & 5.8 \\
\hline MUMBAI & 9.7 & 12.5 & 11.9 & 14.5 \\
\hline OSAKA & 16.6 & 13.3 & 15.0 & 13.2 \\
\hline SEOUL & 18.2 & 16 & 18.0 & 16.7 \\
\hline SHANGH & 14.8 & 15.1 & 16.3 & 16.8 \\
\hline TEHERA & 15.7 & 14 & 13.1 & 17.2 \\
\hline TIAAJI & 18.4 & 17.8 & 18.6 & 18.5 \\
\hline TOKYO & 18 & 10.7 & 15 & 11.5 \\
\hline \multicolumn{5}{|l|}{ Africa } \\
\hline CAIRO & 15.3 & 20.4 & 17.8 & 21.6 \\
\hline JOBURG & 13.6 & 8 & 9.3 & 6.5 \\
\hline LAGOS & 8.8 & 4.6 & 6.3 & 6.0 \\
\hline \multicolumn{5}{|l|}{ Australia } \\
\hline SYDNEY & 18.2 & 14 & 15.8 & 11.4 \\
\hline
\end{tabular}

In general the effect of deposition is to reduce the value of ELR $1 \mathrm{~km}$, and the reduction is stronger for higher local deposition rates, i.e., low value of $T_{\mathrm{li}}$. However, the megacities in the Indian subcontinent plus the city of Cairo have a noticeable increase of ELR $1 \mathrm{~km}$ for BCdp with respect to that of $\mathrm{BCtr}$. A possible mechanism for this happening is if precipitations act mainly on rising air masses outside the $1000 \mathrm{~km}$ 

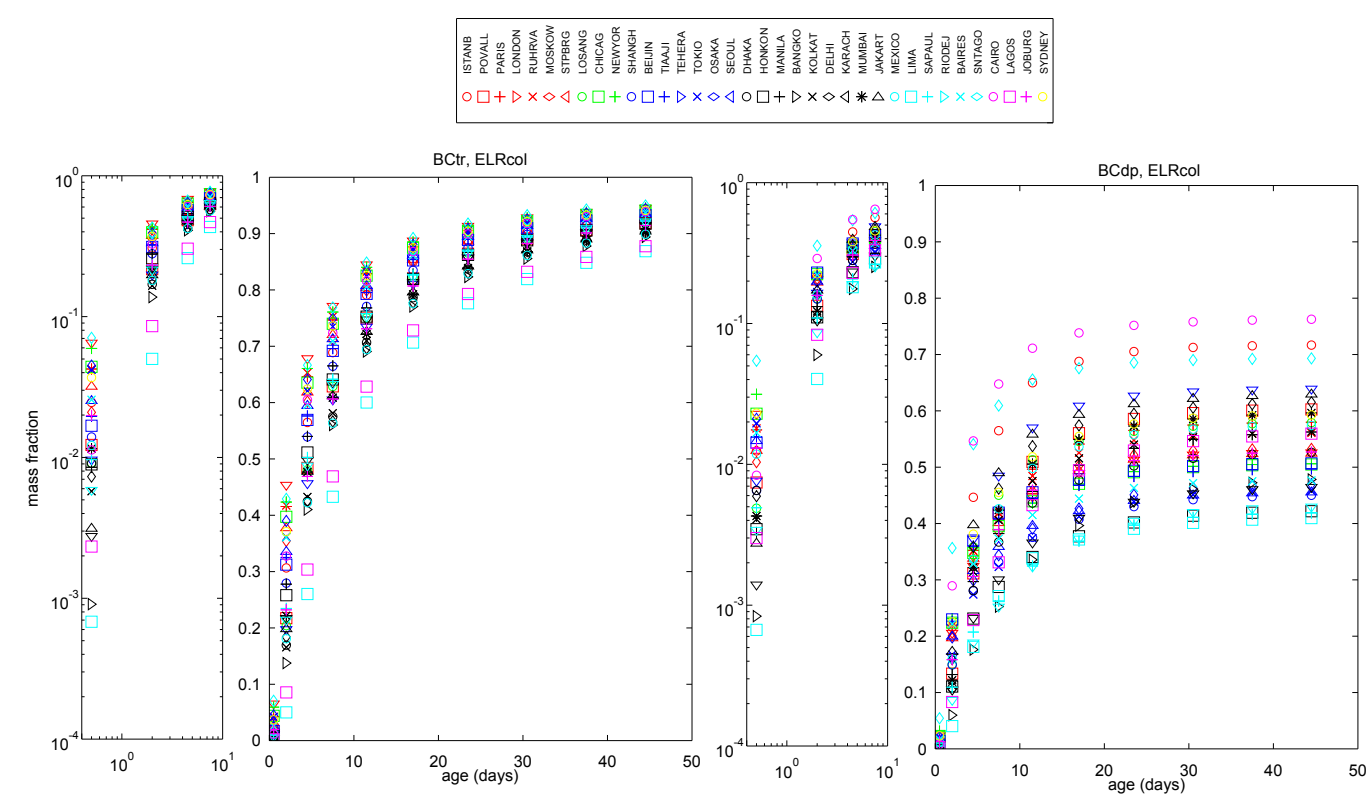

Fig. 10. Fraction of mass transported over $1000 \mathrm{~km}$ away from the source over the whole air column (ELRcol) for BCtr and for BCdp. The normalization is the same used before in Fig. 8.

radius from the source. This seems consistent with the winter monsoon behavior for the Indian subcontinent, as described above. The city of Cairo is instead characterized by an arid local climate (it is the city with the highest $T_{\mathrm{li}}$ ), and therefore, since there are very low levels of precipitations close to the city, it is plausible that precipitations act mainly on rising air masses outside the $1000 \mathrm{~km}$ radius. This is in agreement with the analysis of the deposition for small aerosol particles reported in Kunkel et al. (2012) which, for Cairo, found that deposition happens very far away from the source after the plume has travelled above the Sahara and has reached the inner tropical convergence zone. In general this factor adds variability to the possible range of ELR $1 \mathrm{~km}$ for BCdp, with values spanning about a factor of ten, compared to only a factor of four for BCtr.

The two lowest total values of ELR1 km for BCtr and BCdp are found for Jakarta and Lagos (see Table 2), and it is interesting to examine why. Lagos is the city with the slowest horizontal transport of the plume during the first 3 days after tracer release (Fig. 4a, b, left). Jakarta on the other hand is the second slowest in the range $3<t<14$ days (Fig. $4 a$, b, right). This difference explains also why Jakarta has an initial peak in the value of ELR $1 \mathrm{~km}$ for BCtr (Fig. 8a). When deposition is accounted for, Jakarta is the city with the shortest $T_{\text {li }}$, and therefore the deposition generates a stronger decrease of ELR $1 \mathrm{~km}$ compared to that of any other city (including Lagos). As a consequence the difference between the two lowest values of ELR $1 \mathrm{~km}$ becomes more marked for BCdp. It is also interesting to discuss why Mexico City has initially the lowest value of ELR $1 \mathrm{~km}$ and why it has a quite low overall
ELR $1 \mathrm{~km}$, despite having a quite fast overall horizontal transport (Fig. 4a, b, right). This city is characterized by slow initial transport ( $t<1$ day, see Fig. 4a, b) and has the highest initial plume elevation among all cites (Fig. 5); as a consequence, the plume is initially transported slowly and subsequently, when the transport becomes faster, it is mostly transported at an elevation above $1 \mathrm{~km}$ ATL. The two top low-level exporters irrespective of deposition are the cities of Moscow and Saint Petersburg, and these are cities with a quite fast initial transport (Fig. 4) but also and especially very low average elevation (Fig. 5).

As previously reported by $\mathrm{L} 07$, results for the total mass exported to a distance of more than $1000 \mathrm{~km}$ (ELRcol) are considerably less variable. In particular for the 48-day age class we find a very narrow range of values from $85 \%$ to $95 \%$ (Fig. 10). This is expected since in this case the values should converge approximately towards the same asymptotic limit of $98.8 \%$ for a scalar well mixed in the hemisphere, where an area bounded by the $1000 \mathrm{~km}$ radius covers $1.2 \%$ of the hemisphere. The values of ELRcol for BCtr in the twoweek age class goes from about $60 \%$ to $85 \%$. This is indicative of the value of a scalar subject to a superimposed decay of a similar duration, and indeed this range is quite similar to the cumulated value of ELRcol for BC10, which ranges from about $59 \%$ to $82 \%$. The range of values of $\mathrm{BC} 10$ is again in good agreement with the results of L07 for the 10-day decaying scalar for which they reported a range from $62 \%$ to $84 \%$.

It is interesting to note that Lima, which has clearly the lowest value of ELRcol for any age, was not among the cities 

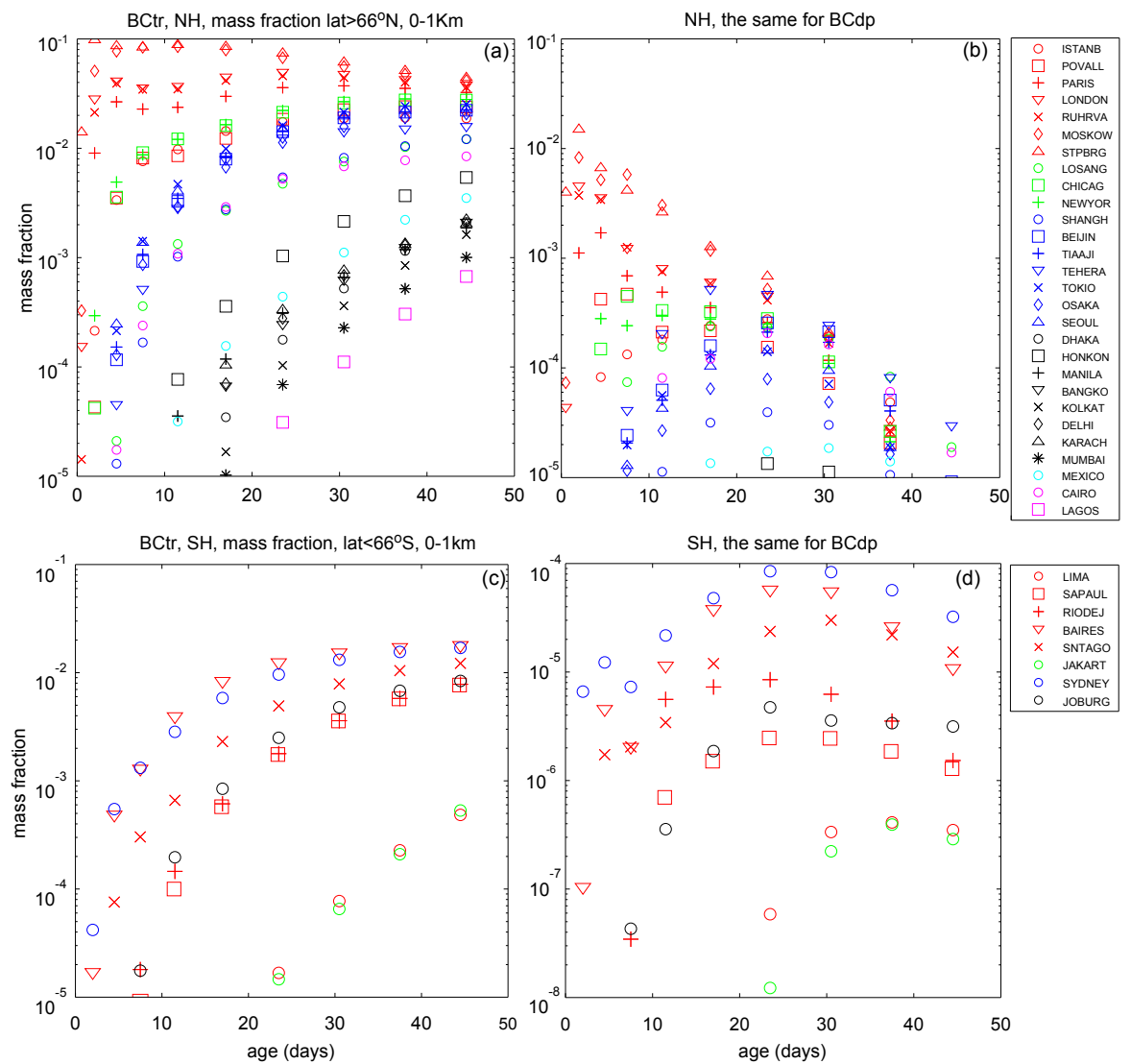

Fig. 11. BCtr (left panels) and BCdp (right panels) mass content in a layer 0-1000 m ATL in the Arctic (a, b) and Antarctic (c, d) regions, scaled for the total mass emitted in any respective age class.

having a very low ELR1 km. This city has an extremely slow horizontal transport (Fig. 4), which is perfectly reflected in the low ELRcol value. However, contrary to Jakarta and Lagos, which have a very low ELR1 km, Lima is not characterized by a very fast uplifting of the plume (Fig. 5), and this increases the value of ELR $1 \mathrm{~km}$. The deposition modifies again the picture by widening the range of values. However, in this case the interpretation is simpler with respect to ELR $1 \mathrm{~km}$ since deposition systematically decreases the value of ELRcol. The cities with the highest values of ELRcol are those characterized by a high value of $T_{\mathrm{li}}$, and Cairo (which is the city with the highest $T_{\mathrm{li}}$ ) becomes the top exporter. The fact that Cairo was not the top low-level exporter for BCdp underlines again that for ELR $1 \mathrm{~km}$ it is very important that the plume is transported at low elevation, which is not the case for Cairo.

\section{Air pollution and $\mathrm{BC}$ deposition in the polar regions}

Analysis of BC concentration in the polar regions is important due to the positive radiative forcing of this species both in the atmosphere and when deposited on snow or ice and also due to the high efficacy of this forcing for climate warming (e.g., Hansen and Nazarenko, 2004; Flanner et al., 2009). We note that a recent paper by Folberth et al. (2012) gives some evidence that the megacities' global radiative forcing is modest, also because of compensating effects of the emitted pollutants. However, this, as discussed by same authors, does not mean that there is not a regional impact on climate (e.g., of the northern European megacities in the Arctic). Our simulations allow us to quantify the efficiency with which $\mathrm{BCdp}$ and $\mathrm{BC}$ tr originating from megacities in different parts of the world can reach the polar atmosphere and deposit on the ice/snow cover. This study is somewhat complementary to the works of Stohl (2006), Stohl and Sodemann (2010) and Hirdman et al. (2010), who studied the possible sources of $\mathrm{BC}$ in the Arctic and Antarctic atmosphere from a receptororiented perspective. Here, we take a source-oriented view by following the emissions from the world's megacities. Recently Kunkel et al. (2012) carried out an extensive study about aerosol deposition from large urban areas, but they kept a more general perspective than our present study, without any particular focus on the polar regions. 


\subsection{Air pollution}

Figure 11a and b show the total BCtr and BCdp mass in the lowest $1 \mathrm{~km}$ ATL of the NH polar atmosphere (north of $66^{\circ} \mathrm{N}$ ), scaled for the mass emitted in the respective age class interval, while Fig. 11c, d provides the same information for the $\mathrm{SH}$ (south of $66^{\circ} \mathrm{S}$ ). As discussed extensively in Stohl (2006), the contribution to mass in this layer in the $\mathrm{NH}$ depends mainly on the latitude of the source, with largest contributions from northern Eurasia. This is confirmed here for the BCtr results. Specifically, we find that releases from Saint Petersburg give the largest fractional contributions of all megacities and for all age classes. As much as $10 \%$ of the emissions can be located in the Arctic already as early as about 2 days after the emission. In fact, the contribution decreases after about 2 weeks, as the Saint Petersburg plume is initially preferably transported to the north and subsequently disperses into the entire NH. Similar behavior could be expected for pollution export from other Baltic and Scandinavian cities that are relatively close to Saint Petersburg. This group of cities is consequently likely to be the largest "localized" contributor of anthropogenic pollution in the lower layer of the Arctic atmosphere for substances with lifetimes on the order of days to a few weeks. Furthermore, while Moscow makes a smaller BCtr fractional contribution to the pollution in the Arctic atmosphere during the first 3 days after emission, the contributions at later times are almost identical to those of Saint Petersburg. The age class sampling allows appreciating that, for any substance with a decaying timescale of less than about 10 days, the contributions from non-European cities are very small. Only after this elapsed time do contributions from North American megacities start to be more relevant, and soon after also from east Asian midlatitude cities. Contributions from tropical locations are, even for the last age class considered (48 days), an order of magnitude smaller than contributions from Saint Petersburg. Table 3 (column 1 and 3) reports the cumulative amount of mass irrespective of the age classes and expressed both as mass and as a percentage of total emitted mass. The table confirms that cities in Europe have significantly larger fractional contributions, but in terms of absolute numbers (i.e., taking into account also the different emission strengths) the extended New York megacity is the largest contributor and Tokyo, Seoul and Beijing have numbers comparable to those of most European cities. However, we remind the reader that, as shown by the age class plots, these cities have smaller contributions relative to European cities when the lifetime is significantly shorter than 48 days.

When taking into account deposition processes (BCdp), the fractional contributions from all cities become much smaller (Fig. 11b). However, the reductions are particularly large for non-European cities, and, thus, significant contributions to the BCdp loading in the lowest $1 \mathrm{~km}$ of the Arctic atmosphere are confined to northern European sources with small contributions from North American cities. Saint Pe- tersburg and Moscow give similarly high contributions in the age classes going from 2 to 20 days, although both London and the Ruhr Valley are also relevant. The cumulative numbers reported in Table 3 (column 2 and 4) show that, with our definitions of the megacities' extension, for BCdp all the megacities in Asia contribute less than the sole city of Saint Petersburg and that the extended New York megacity has a similar contribution to Saint Petersburg despite having almost 20 times the population.

Figure 12 reports the fraction of mass of BCdp and BCtr in the Arctic free troposphere and stratosphere, $2-9 \mathrm{~km}$ (a, b) and $9-30 \mathrm{~km}$ (c, d) above sea level, respectively. For Bctr, the contributions in the free troposphere are similar to those observed in the first layer $(0-1 \mathrm{~km})$ but with higher values from midlatitude Asian and North American cities, which are as large as those of European cities as early as two weeks after the release. Also, with the increase of the plume age, the contributions from sources in the tropics become noticeable. This again suggests that, if a superimposed decay process is investigated, a decaying timescale of about a week would give clearly the largest contributions from European and North American cities, while longer decaying timescales would give substantial contributions from Asian megacities. If deposition is accounted for (Fig. 12b), the contribution from European megacities becomes more significant even for longer superimposed decaying timescales. However, only in the case of substances with a superimposed decay of less than 3 days would the contribution from midlatitude Asian cities be negligible. This is in contrast to the $0-1 \mathrm{~km}$ ATL layer, where European sources are totally dominant.

Moving to the stratosphere, Fig. 12c shows that the most efficient transport of BCtr mass into the Arctic stratosphere is from the midlatitude Asian and North American megacities. The differences between these and other sources are better appreciated on a linear scale (insert in Fig. 12c). Looking in more detail it is possible to see that initially (age class of up to 3 days) the most efficient in contributing to the $\mathrm{BCtr}$ mass in this upper layer are Northern European cities but soon thereafter midlatitude Asian and North American cities become noticeably more efficient. This suggests a quite complex scenario in case a superimposed decay is considered, with dominant contribution from different regions of the $\mathrm{NH}$ depending on the lifetime of the chemical species. Similar lifetime dependence could be observed in the case of BCdp, although in this case the fractions of mass reaching these layers of the atmosphere are much lower. Interestingly the Po Valley megacity becomes in this case the most efficient source in transporting mass into the Arctic stratosphere. In Table 3 (last two columns) the total mass transported in the polar stratosphere for BCtr and BCdp is reported, and it is possible to see how the Po Valley stands out as the largest contributor to BCdp in the Arctic stratosphere.

The current results - reporting a contribution mainly from European megacities to the mass of BC in the lowest kilometer of the Arctic atmosphere and a progressively increasing 
Table 3. The Table reports (1) the cumulative value of mass of BCdp deposited (Dep66) in the polar regions $\left(\mid\right.$ Lat $\left.\mid>66^{\circ}\right)$; $(2)$ the mass of BCtr and Bcdp suspended (Sus66) in the polar atmosphere up to an elevation $\mathrm{h}<1 \mathrm{~km}$ above terrain; (3) The mass of BCdp deposited over land during winter in the northern hemisphere for Lat $>40^{\circ}$ (Dep401) (4) the mass in the polar stratosphere (Strat66). The mass is reported in tons, $\mathrm{kg}$ and as a fraction $(\%, \%)$ of the total averaged emitted mass within the 48-day age class limit.

\begin{tabular}{|c|c|c|c|c|c|c|c|c|c|c|}
\hline Cities & $\begin{array}{l}\text { BCtr } \\
\text { Sus66 } \\
\text { ton }\end{array}$ & $\begin{array}{l}\text { Bcdp } \\
\text { Sus66 } \\
\mathrm{kg}\end{array}$ & $\begin{array}{l}\text { Bctr } \\
\text { Sus66 } \\
\%\end{array}$ & $\begin{array}{l}\text { BCdp } \\
\text { Sus66 } \\
\% o\end{array}$ & $\begin{array}{l}\text { BCdp } \\
\text { Dep66 } \\
\text { ton }\end{array}$ & $\begin{array}{l}\text { BCdp } \\
\text { Dep66 } \\
\%\end{array}$ & $\begin{array}{l}\text { Bcdp } \\
\text { Dep401 } \\
\text { ton }\end{array}$ & $\begin{array}{l}\text { BCdp } \\
\text { Dep401 } \\
\%\end{array}$ & $\begin{array}{l}\text { BCtr } \\
\text { Strat66 } \\
\text { ton }\end{array}$ & $\begin{array}{l}\text { BCdp } \\
\text { Strat66 } \\
\text { kg }\end{array}$ \\
\hline \multicolumn{11}{|l|}{ Europe } \\
\hline ISTANB & 4.01 & 40 & 1.43 & 0.14 & 19.4 & 0.89 & 305 & 45.6 & 1.07 & 38 \\
\hline LONDON & 31.4 & 569 & 4.09 & 0.74 & 256 & 4.35 & 795 & 44.4 & 2.58 & 36 \\
\hline MOSCOW & 54.8 & 1423 & 6.2 & 1.61 & 382 & 5.61 & 1544 & 75 & 3.42 & 71 \\
\hline PARIS & 19.9 & 231 & 3.02 & 0.35 & 126 & 2.49 & 879 & 57.2 & 2.59 & 81 \\
\hline POVALL & 31.3 & 276 & 1.61 & 0.14 & 249 & 1.67 & 2084 & 46 & 9.96 & 626 \\
\hline RUHRVA & 40.4 & 723 & 3.86 & 0.69 & 355 & 4.41 & 1421 & 58.2 & 3.87 & 98 \\
\hline STPBRG & 31.1 & 886 & 6.94 & 1.98 & 326 & 9.43 & 679 & 67 & 1.53 & 34 \\
\hline \multicolumn{11}{|l|}{ North America } \\
\hline CHICAG & 6.06 & 56 & 1.9 & 0.17 & 12.4 & 0.51 & 456 & 61.7 & 1.98 & 35 \\
\hline LOSANG & 9.24 & 211 & 0.56 & 0.13 & 104 & 0.81 & 388 & 9.91 & 9.88 & 276 \\
\hline NEWYOR & 97.2 & 764 & 1.95 & 0.15 & 180 & 0.47 & 3169 & 27.3 & 29.5 & 582 \\
\hline \multicolumn{11}{|c|}{ Mexico \& South America } \\
\hline BAIRES & 7.02 & 18 & 1.06 & 0.03 & 6.08 & 0.12 & - & - & 1.96 & 29 \\
\hline LIMA & 0.08 & 0 & 0.01 & 0 & 0.27 & 0.01 & - & - & 0.43 & 3 \\
\hline MEXICO & 1.14 & 11 & 0.11 & 0.01 & 12.4 & 0.15 & 68.1 & 2.72 & 3.99 & 156 \\
\hline RIODEJ & 1.87 & 3 & 0.29 & 0 & 1.2 & 0.02 & - & - & 2.05 & 21 \\
\hline SAPAUL & 3.21 & 2 & 0.29 & 0 & 1.73 & 0.02 & - & - & 3.54 & 27 \\
\hline SNTAGO & 4.03 & 11 & 0.55 & 0.01 & 9.2 & 0.16 & - & - & 2.17 & 44 \\
\hline \multicolumn{11}{|l|}{ Asia } \\
\hline BANGKO & 0.57 & 1 & 0.06 & 0 & 0.87 & 0.01 & 11.6 & 0.74 & 3.04 & 51 \\
\hline BEIJIN & 20 & 168 & 1.26 & 0.11 & 49.2 & 0.4 & 780 & 20.9 & 9.2 & 164 \\
\hline DELHI & 0.74 & 1 & 0.07 & 0 & 2.66 & 0.03 & 14.8 & 0.56 & 4.12 & 169 \\
\hline DHAKA & 2.48 & 5 & 0.06 & 0 & 10.9 & 0.03 & 64.3 & 0.61 & 16.8 & 363 \\
\hline HONKON & 10.7 & 31 & 0.18 & 0.01 & 25.1 & 0.06 & 87.4 & 0.64 & 27.9 & 345 \\
\hline JAKART & 0.16 & 0 & 0.01 & 0 & 0.28 & 0.00 & - & - & 1.33 & 14 \\
\hline KARACH & 0.17 & 1 & 0.07 & 0 & 0.84 & 0.04 & 5 & 0.82 & 0.77 & 51 \\
\hline KOLKAT & 0.43 & 1 & 0.04 & 0 & 1.52 & 0.02 & 10.5 & 0.44 & 3.5 & 103 \\
\hline MANILA & 0.61 & 1 & 0.06 & 0 & 1.07 & 0.01 & 9.24 & 0.39 & 3.11 & 63 \\
\hline MUMBAI & 0.45 & 2 & 0.03 & 0 & 2.66 & 0.02 & 19.7 & 0.48 & 4.28 & 271 \\
\hline OSAKA & 11.9 & 36 & 1.09 & 0.03 & 18.2 & 0.22 & 46.5 & 1.82 & 7.27 & 94 \\
\hline SEOUL & 45.6 & 195 & 1.34 & 0.06 & 58.1 & 0.22 & 245.6 & 3.09 & 19.6 & 194 \\
\hline SHANGH & 5.92 & 18 & 0.57 & 0.02 & 8.85 & 0.11 & 60.2 & 2.48 & 5.52 & 71 \\
\hline TEHERA & 4.42 & 96 & 0.96 & 0.21 & 35. & 1.01 & 312.8 & 28.7 & 2.31 & 60 \\
\hline TIAAJI & 12.9 & 87 & 1.28 & 0.09 & 28.6 & 0.37 & 473.5 & 20 & 5.77 & 98 \\
\hline TOKYO & 29.2 & 117 & 1.45 & 0.06 & 42.0 & 0.27 & 104.2 & 2.2 & 13 & 188 \\
\hline \multicolumn{11}{|l|}{ Africa } \\
\hline CAIRO & 3.39 & 66 & 0.46 & 0.09 & 22.1 & 0.39 & 191 & 10.8 & 1.95 & 97 \\
\hline JOBURG & 5.11 & 4 & 0.34 & 0 & 7.06 & 0.06 & - & - & 4.3 & 77 \\
\hline LAGOS & 0.06 & 0 & 0.02 & 0 & 0.36 & 0.01 & 2.84 & 0.32 & 0.53 & 25 \\
\hline \multicolumn{11}{|l|}{ Australia } \\
\hline SYDNEY & 8.98 & 46 & 0.92 & 0.05 & 19.39 & 0.26 & - & - & 3.21 & 82 \\
\hline Total NH & 476.09 & 6016 & & & 2330.2 & & 14227.28 & & 199.04 & 4440 \\
\hline Total SH & 30.46 & 84 & & & 45.2 & & & & 18.99 & 297 \\
\hline
\end{tabular}




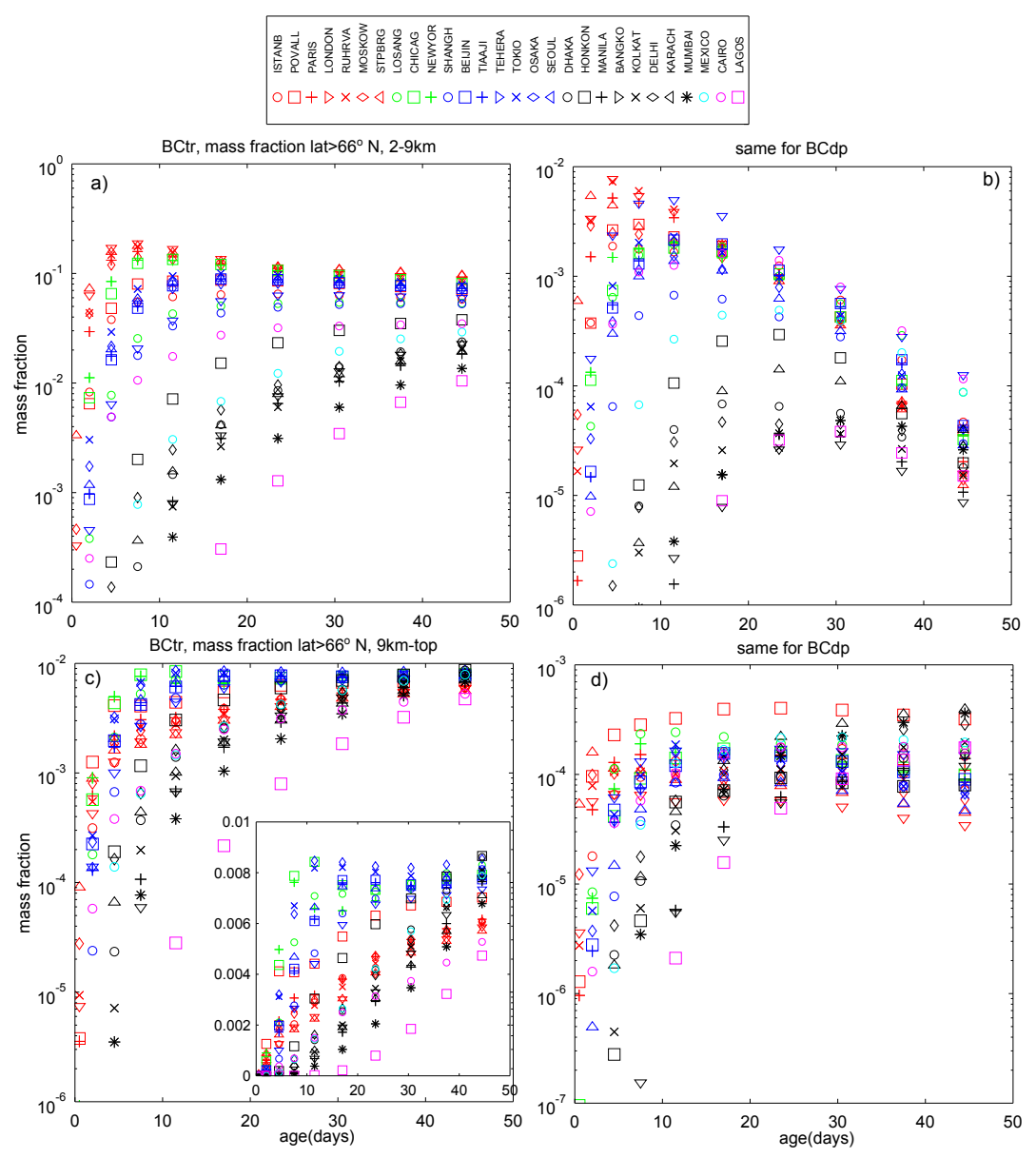

Fig. 12. BCtr (left panels) and BCdp (right panels) mass content in the Arctic region scaled for the total mass emitted in the respective age class for layers of the atmosphere extending from 2 to $9 \mathrm{~km}(\mathbf{a}, \mathbf{b})$ and from 9 to $30 \mathrm{~km}(\mathbf{c}, \mathbf{d})$ above sea level. The insert in (c) shows the same information but on a linear scale.

contribution of North American and east Asian megacities when moving up to the free troposphere and the stratosphere - are in agreement with the findings of Hirdman et al. (2010), who reported a substantial contribution to BC measurements at lower altitude stations only from northern Eurasian sources, while significant contributions from more remote sources (e.g., east Asian) were observed for measurements on top of the Greenland ice sheet.

\subsection{Deposition}

For quantifying $\mathrm{BC}$ deposition in the polar regions we consider the accumulated mass over an area of interest during a period (i.e., year, season). When normalized quantities are shown, this is done considering the total mass available for deposition during the period considered, given by the initial mass suspended in the atmosphere at the beginning of the period plus the mass emitted during the period. Figure 13 shows the normalized (left panels) and unnormalized (right panels) deposition north/south of $66^{\circ} \mathrm{N} / 66^{\circ} \mathrm{S}$ within 48 days from the release. The values cumulated over all age classes are reported in Table 3. Saint Petersburg has the largest fraction of its BCdp emissions deposited in the Arctic (9.4\%), followed by Moscow $(5.6 \%)$ and the Ruhr Valley and London (both about $4 \%$ ). However, the absolute deposition in the Arctic is comparable for these cities, and also the Po Valley and Paris cause significant deposition values. The North American megacities of New York and Los Angeles give normalized deposition values that are more than an order of magnitude smaller, but because of the larger BC emissions of these American cities, the actual deposition values are only about 2 to 3 times lower than the contributions of European megacities. Absolute and relative contributions from megacities on other continents are much lower. This means, as shown in Table 3, that the sole city of Saint Petersburg (population 2.6 million based on the GPWv3 database and with our definitions of his extension) produces a BCdp deposition in the Arctic that is marginally larger than the BCdp deposition from all the megacities in Asia (population roughly 500 million). This seems to confirm again that most of the Arctic 

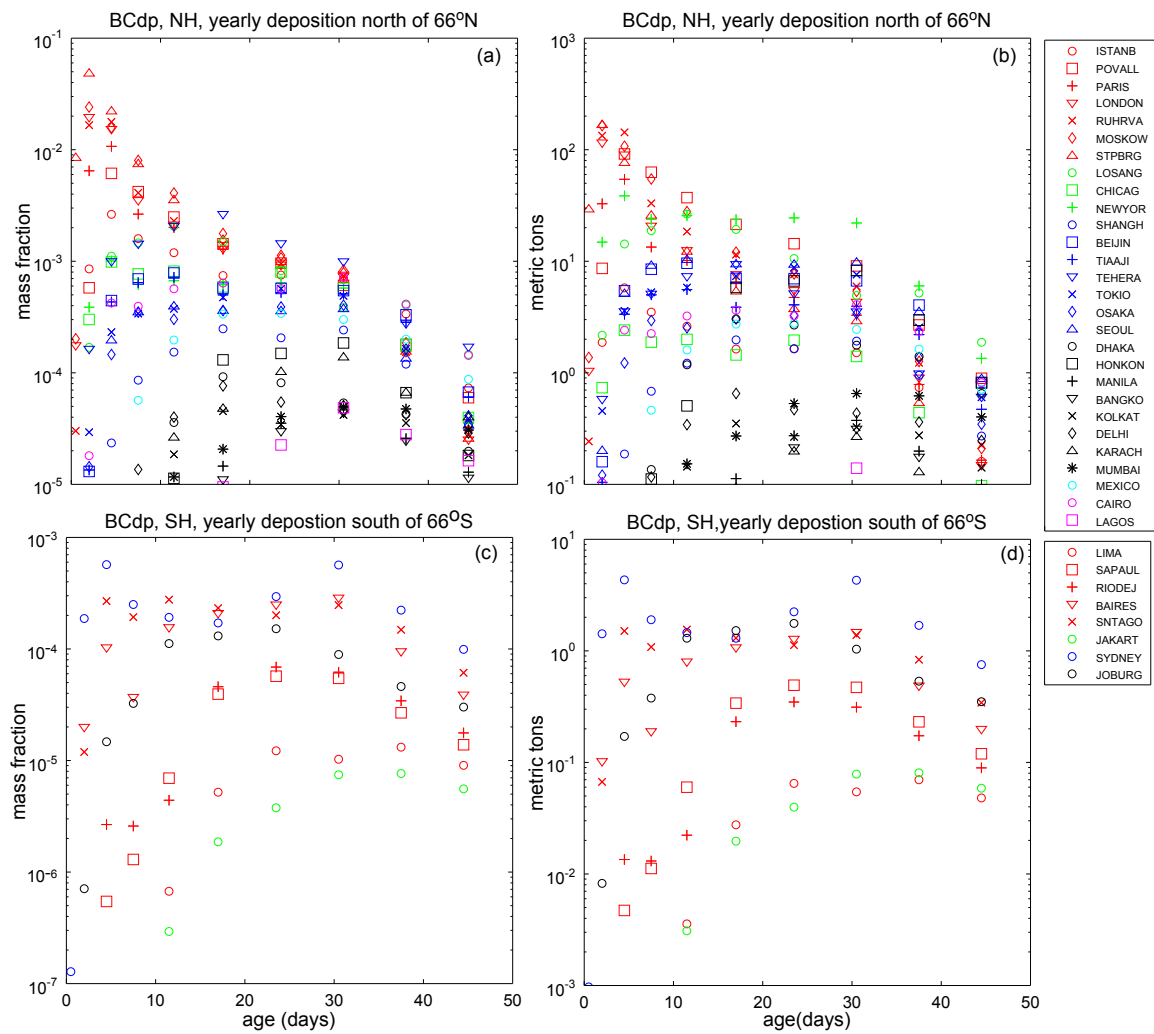

Fig. 13. Deposition of $\mathrm{BC}$ at latitudes north of $66^{\circ} \mathrm{N}(\mathbf{a}, \mathbf{b})$ and south of $66^{\circ} \mathrm{S}(\mathbf{c}, \mathbf{d})$, relative to the mass available for deposition (left) and absolute value (right).

BC deposition from megacities must be attributed to northern Eurasian sources.

Looking in detail to the deposition fractions for Asian megacities in Table 3, it is interesting to note that Teheran, with a value above $1 \%$, stands out with respect to all other cities of comparable or more northern latitude. This is related to the arid conditions that allow for a considerable fraction of the mass to be exported away from the source $\left(T_{\mathrm{li}}=8.2\right.$ days). This result agrees well with the analysis of Kunkel et al. (2012) that found for cities in arid climate the largest remote aerosol deposition potential.

The BCdp deposition over land during the winter season for latitudes north of $40^{\circ}$ is also reported in Table 3 (columns 7 and 8). During winter, a significant fraction of land above this latitude may be covered by snow, and the BC deposited may have an influence in accelerating the melting of the snow in spring (e.g., Quinn et al., 2008; Flanner et al., 2009). For this region, the fractional contributions from European and North American megacities are comparable, and the Asian megacities of Beijing, Tianjin, and Teheran give significant fractional contributions followed by Cairo in northern Africa. Similar considerations are valid for the absolute mass deposition, and in this case New York City emerges as the largest contributor to deposited BCdp.

\subsection{The Southern Hemisphere}

Although there are just eight megacities in the $\mathrm{SH}$, according to the emission inventories used, they represent about $12 \%$ of the total emission (see Fig. 2) in the SH from the South Pole to a latitude of $25^{\circ} \mathrm{S}$. The export of BCtr and BCdp from $\mathrm{SH}$ megacities to the Antarctic region is much smaller than from $\mathrm{NH}$ megacities to the Arctic, and even export efficiencies relative to the emission strength are lower. In fact, due to the generally longer distances of the SH megacities to the Antarctic region, the fraction of $\mathrm{BCtr}$ mass transported to the lower layer of the Antarctic atmosphere $(0-1 \mathrm{~km})$ reaches maximum values of $2 \times 10^{-2}$ (Fig. 11c) in the last age class. Values for ages of less than about 20 days are lower and there is no peak in the early age class, again due to the considerable distance of the sources from the polar region. Moreover, these values are reached only for Buenos Aires and Sydney, while the other megacities, and especially Lima and Jakarta, give substantially lower contributions. For the depositing tracer $\mathrm{BCdp}$, no more than a fraction of $10^{-4}$ of the emitted mass in any age class reaches the Antarctic atmosphere (Fig. 11d). Summary numbers, cumulating the contribution from all age classes, are reported in Table 3 for both $\mathrm{BCtr}$ and BCdp. They show that for BCtr the total megacity emissions in the $\mathrm{SH}$ generate a suspended mass in the 
Antarctic atmosphere comparable to that produced by the single city of St. Petersburg in the Arctic. If deposition is furthermore taken into account, the suspended mass is entirely negligible with less than $100 \mathrm{~kg}$ of suspended mass overall.

The fraction of BCdp mass depositing south of $66^{\circ} \mathrm{S}$ is also very low. Our simulations estimate a total annual deposition of BCdp in the Antarctic by all the megacities of about 45 tons (see Table 3), and most of it comes from just four megacities, Sydney, Johannesburg, Santiago and Buenos Aires, with a marginal contribution from Sao Paulo and Rio de Janeiro. The comparison with the total deposition of 2330 tons of BCdp from NH megacities in the Arctic shows that this deposition is very small, also considering that the total emission from $\mathrm{NH}$ megacities is just about 5.5 times the $\mathrm{SH}$ megacity emissions. However, this 45 tons of BCdp deposition is comparable to the local emissions, below $60^{\circ} \mathrm{S}$, of BC from shipping (100 tons) as reported by Stohl and Sodemann (2010) based on the emission inventory of Bond et al. (2007), with tourist ships contributing about 20 tons (Stohl and Sodemann, 2010). Also, if we consider the $12 \%$ megacity emissions representative of all $\mathrm{SH}$ emissions south of $25^{\circ} \mathrm{S}$, we can estimate that less than 400 tons of BCdp are deposited in the South Pole region from all continental sources.

\section{Exposure of human population}

In this section, population $(P)$ and annual mean ground level concentration (GLC) maps are combined to derive simple but quantitative measures of the exposure of the human population to air pollution from megacities. Particular focus will be on the relative importance of population exposure inside and outside the megacity. We use the GLC multiplied by population $(\mathrm{CmP})$ as a measure of total population exposure to air pollution and define this metric as a function of time (i.e., for any age class),

$\mathrm{CmP}(t)=\mathrm{CmP}_{i t}=\sum_{\text {all } i j} P_{i j} \sum_{l=1}^{i t} \mathrm{GLC}_{i j, l}$.

Here $i, j$ are grid indices, indicating that the metric is integrated over the entire globe, and it is the index of the age class considered. Therefore, $\mathrm{CmP}$ is a function of time since emission, and the concentration used is given by the summation of the concentration associated with the current and the previous age classes. The values computed for the 48-day age class are reported in Table 1 for both BCtr and BCdp. Notice that since the lifetime of $\mathrm{BCdp}$ is substantially shorter than 48 days for all cities, the metric measures the total impact of BCdp. The table shows that the largest values of $\mathrm{CmP}$ are reached for the megacities in Asia, with Dhaka setting the records of 149 and $104\left(10^{10} \mathrm{ng} \mathrm{m}^{-3}\right.$ people), respectively, for BCtr and BCdp. The first non-Asian megacity is the extended New York area which ranks seventh, with values of 40 and 22 for BCtr and BCdp, while the first-ranking European city is Moscow with CmP values of 19 and 14 .

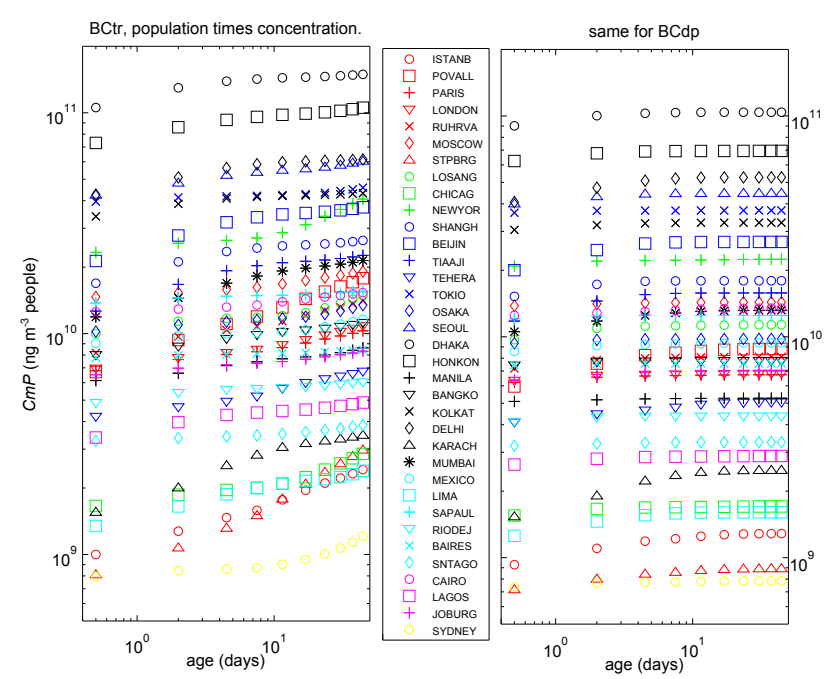

Fig. 14. The CmP metric for BCtr (left) and BCdp (right) as a function of tracer age.

Figure 14 shows the values for all the age classes, and it can be seen that when deposition is considered the $\mathrm{CmP}$ exposure metric for BCdp (Fig. 14, right) is quite flat and determined mainly by the exposure on the very first day. This is due to a combination of three factors: (i) the highest population density at the location of the release (i.e., within the megacity), (ii) all BCdp being initially located near the surface, and (iii) the quick loss of BCdp mass with time. This suggests that most of the population exposure to BCdp occurs within or very close to the megacity. Also for the conserved tracer BCtr, $\mathrm{CmP}$ values do not grow substantially after the first day (Fig. 14, left), suggesting that even for longlived pollutants most of the population exposure occurs in the city or its vicinity. This is also the reason why the $\mathrm{CmP}$ values for BCtr and BCdp are quite similar for most cities, suggesting that population exposure is not very sensitive to a substance's lifetime if it is longer than a day.

In Table 1 we also report the population-weighted concentration for the city $\left(\mathrm{PWC}_{\mathrm{city}}\right)$ for $\mathrm{BCtr}$ and $\mathrm{BCdp}$ :

$\mathrm{PWC}_{\text {city }}=\frac{1}{P_{\text {city }}} \sum_{i j \in \text { city }} P_{i j} \sum_{l=1}^{\mathrm{Na}} \mathrm{GLC}_{i j, l}$,

i.e., the same as the $\mathrm{CmP}$ metric but computed only for the grid cells defining each megacity, with GLC integrated over all the age classes $\left(N_{\mathrm{a}}=10\right)$ and normalized with the megacity's total population $\left(P_{\text {city }}\right)$. This metric measures the concentration to which the population inside the city is exposed on average. Some interesting features arise when comparing the megacities. The highest value of PWC can be found in Asian megacities, with Seoul having values of 1621 and $1535 \mathrm{ng} \mathrm{m}^{-3}$, respectively, for BCtr and BCdp. The lowest values are registered for Istanbul, respectively 64 and $61 \mathrm{ng} \mathrm{m}^{-3}$ for BCtr and BCdp. It should be noted that for 
cities covering only one cell this value is the same as the maximum concentration in the domain, while it can be significantly lower for larger megacities.

A further parameter of interest is $\mathrm{CmP}$ normalized by $\mathrm{CmP}$ obtained when integrating only over the megacity grid cells, called here $\mathrm{CmP}_{\mathrm{c}}$. This metric $\left(\mathrm{CmP} / \mathrm{CmP}_{\mathrm{c}}\right)$ measures the total population exposure relative to the exposure inside the city. These values are plotted as a function of the age in Fig. 15. First, we note that for the nondepositing tracer BCtr, several cities have an impact on surrounding regions which is at least half as large as on the population of the city itself (i.e., $\mathrm{CmP} / \mathrm{CmP}_{\mathrm{c}}>1.5$ ), but few cities have an impact outside the city's boundaries larger than the impact inside the city boundary (i.e., $\mathrm{CmP} / \mathrm{CmP}_{\mathrm{c}}>2$ ) and only three cities reach this thresholds if deposition is taken into account (Fig. 15, right panel). For BCtr, Saint Petersburg shows the largest $\mathrm{CmP} / \mathrm{CmP}_{\mathrm{c}}$ values but only for ages greater than 10 days. This is due both to the fact that it is surrounded, but not closely surrounded, by relatively densely populated areas and that it has the smallest population among the cities considered (thus reducing the impact inside the city boundaries). Southern Hemisphere megacities show generally somewhat lower $\mathrm{CmP} / \mathrm{CmP}_{\mathrm{c}}$ values, with minima obtained for Buenos Aires and Sao Paulo, since these are densely populated areas surrounded by relatively sparsely populated areas and are close to the ocean. In the NH, Tokyo stands out with the lowest value of the ratio, since most of its pollution is exported to the ocean. If deposition is accounted for (BCdp), Sydney also has a very low $\mathrm{CmP} / \mathrm{CmP}_{\mathrm{c}}$ ratio, while the cities showing highest values of $\mathrm{CmP} / \mathrm{CmP}_{c}$ are the densely populated Chinese megacities of Tianjin and Beijing, which are actually surrounded by regions with extremely high population density outside the city boundaries, and the city of Karachi. This last city shows high impact only after about 5 days; thus this should be due to the Karachi's plume impacting densely populated Indian urban areas. It is interesting to note that the cities with a high $\mathrm{CmP} / \mathrm{CmP}_{\mathrm{c}}$ ratio also have a quite high index of low-level BCdp export (ELR1km, Fig. 8b).

In general and especially for the BCdp tracer, it seems that the impact of megacities on population outside their boundaries relative to their impact inside city boundaries is low, with only three of the megacities (Tianjin, Beijing and Karachi) showing an impact comparable to or greater than the impact inside the cities, while most of the cities have $\mathrm{CmP} / \mathrm{CmP}_{\mathrm{c}}<1$.4. It is also of some interest to note that based on the time related behavior of this index one could speculate whether the impact on population is transnational. For example when deposition is involved, the Chinese megacities of Tianjin and Beijing have an index $\mathrm{CmP} / \mathrm{CmP}_{\mathrm{c}}>1.6$ already in the first age class (less than a day) and this value does not grow substantially with age. Therefore, most of their influence is on national population. Conversely, Karachi reaches a similar index only in the second age class ( 3 days) so it is probably related to transboundary pollution transport.
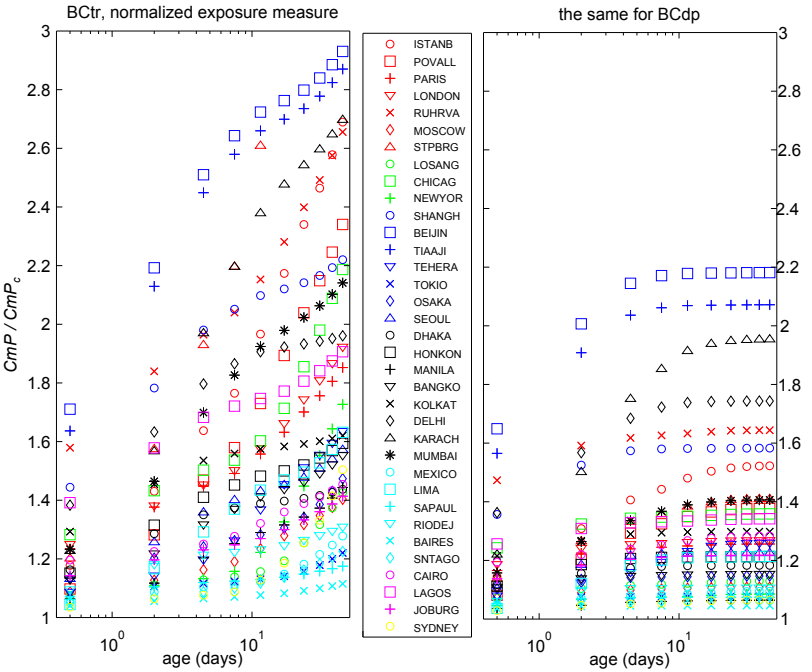

Fig. 15. $\mathrm{CmP} / \mathrm{CmP}_{\mathrm{c}}$ as a function of tracer age, for BCtr (left) and $\mathrm{BCdp}$ (right). In the left panel, $\mathrm{CmP} / \mathrm{CmP}_{\mathrm{c}}$ values for the city of St. Petersburg exceed the scale and reach about 4.5 at 48 days.

Based on the age class spectrum it is also easily possible to extrapolate the behavior for decaying scalars, but in the case of BCdp any superimposed decay with characteristic time greater than about ten days would basically leave the results unchanged.

\section{Summary and conclusions}

A study of the characteristics of air pollution plumes dispersing from a group of 36 of the world's megacities has been performed using the Lagrangian particle model FLEXPART. The study focuses on plumes generated by BC emissions. BC was chosen since (i) this is a species well suited for a Lagrangian investigation because it can be represented in a linear modeling framework, (ii) it is representative of combustion-related emissions and (iii) it is an important air pollutant and short-lived climate forcer. Based on BC emissions two artificial tracers were modeled, a purely conserved tracer with a cut-off lifetime at 48 days - BCtr - and one resembling more closely the properties of true $\mathrm{BC}$ and subject to wet and dry deposition - BCdp. Four aspects of megacities' plumes have been investigated: (1) physical dispersion characteristics, e.g., transport distance and average altitude; (2) pollution export in the lower troposphere over more than one thousand kilometers (ELR1 km); (3) concentrations and deposition of BC in the polar regions; and (4) exposure of human population with a focus on comparing the inside-thecity versus outside-the-city exposure values.

Although local conditions can be very important, the main factor influencing the physical dispersion characteristics was found to be the latitude of the emitting cities; initially, plumes from higher-latitude cities travel faster, but after about three 
days the higher elevation reached by the plumes at tropical/subtropical latitude generated a complementary faster horizontal advection. The proximity to the ocean was found to be an important factor in determining a fast early phase of plume transport. Among the European megacities the Po Valley shows a unique behavior since the tracer is trapped there by mountains on three sides, which strongly limits the early phase of transport, but, overall, in the NH the megacity with the slowest horizontal transport up to 10 days is the tropical city of Lagos. However, Lima is the city showing the slowest horizontal transport.

It was found that the cities showing a high level of regional pollution export in the lower troposphere (ELR1km) are generally high-latitude cities since these are characterized by an initially fast transport and by a low plume elevation. The influence of deposition was mainly to reduce the value of ELR $1 \mathrm{~km}$, and this reduction was found to be stronger for cities with low values of the local characteristic deposition timescale $T_{\mathrm{li}}$. However, a few exceptions (Indian subcontinent megacities and Cairo) were observed where the value of ELR $1 \mathrm{~km}$ increased due to the effect of deposition. This behavior could be explained with the possibility of lowlevel transport at a distance larger than $1000 \mathrm{~km}$ followed by a preferential deposition in uplifting air masses. A good agreement between our simulations and previous results by Lawrence et al. (2007) for ELR1 km was observed for a nondepositing scalar with a 10-day decaying timescale.

The contribution to lower-tropospheric concentrations and deposition in the Arctic must be mainly attributed to northern European megacities (St. Petersburg, Moscow, London and Ruhr Valley). Based on the emission inventory used, the sole city of St. Petersburg contributes up to $10 \%$ of the BC emission north of $60^{\circ} \mathrm{N}$ during winter, and when deposition is considered (BCdp) its contribution to suspended mass of BCdp in the lower $1 \mathrm{~km}$ of the Arctic atmosphere and deposition on the Arctic surface is larger than that of the whole group of Asian megacities (population about 500 million). When considering the upper layer of the Arctic troposphere $(2-9 \mathrm{~km})$ and stratosphere $(9-30 \mathrm{~km})$, the contribution of remote sources becomes progressively more important. In the stratosphere the contribution from Asian megacities is the largest, followed by those from North American megacities and European megacities, with the Po Valley standing out among this latter group. However, all the megacities can be considered significant for pollution in this layer of Arctic atmosphere.

The export of BCtr and BCdp from Southern Hemisphere megacities to the Antarctic region is much smaller than from Northern Hemisphere megacities to the Arctic, and even the export efficiency relative to the emission strength is lower. Our simulations estimate a total annual deposition of BCdp in the Antarctic by all the Southern Hemisphere megacities of about 45 tons, compared to the total deposition of 2330 tons of BCdp from Northern Hemisphere megacities in the Arctic. Note that the contribution by all megacities to the
BCdp deposition in the Antarctic is, therefore, estimated to be smaller than the $\mathrm{BC}$ emissions coming from the local shipping activities.

We remind the reader, however, that emissions from individual cities can be very different between different emission inventories, and this uncertainty is implicit in our analysis.

Regarding the exposure of the human population, we found that for the passive tracer BCtr ten megacities have an impact outside their boundaries greater than their impact inside the cities' boundaries. If BCdp is considered, only three megacities have larger impacts outside than inside their boundaries. These three cities are Beijing, Tianjin and Karachi, and they were shown to have quite high values of low-level pollution export - ELR $1 \mathrm{~km}$. Therefore the combined conditions of high ELR $1 \mathrm{~km}$ and high population densities outside cities' boundaries were necessary to have a higher impact on population outside the city than that on population inside the city. In general, however, it was found that most of the impact on population is related to pollution inside the city boundaries.

Acknowledgements. This study was funded in the European Union's Seventh Framework Programme FP/2007-2013 within the projects MEGAPOLI (grant agreement no. 212520) and ECLIPSE (grant agreement no. 282688) and by the Norwegian Research Council in the framework of the project CLIMSLIP.

Edited by: A. Baklanov

\section{References}

Baumbach, G., Vogt, U., Hein, K. R. G., Oluwole, A. F., Ogunsola, O. J., Olaniyi, H. B., and Akeredolu, F. A.: Air pollution in a large tropical city with a high traffic density - results of measurements in Lagos, Nigeria, Sci. Total Enviro., 169, 25-32, doi:1016/00489697(95)04629-F, 1995.

Bigi, A., Ghermandi, G., and Harrison, R. M.: Analysis of the air pollution climate at a background site in the Po valley, J. Environ. Monit., 14, 552-563, 2012.

Bond, T. C., Bhardwaj, E., Dong, R., Jogani, R., Jung, S., Roden, C., Streets, D. G., Fernandes, S., and Trautmann, N.: Historical emissions of black and organic carbon aerosol from energy-related combustion, 1850-2000, Global Biogeochem. Cy., 21, GB2018, doi:10.1029/2006GB002840, 2007.

Butler, T. M, Lawrence, M. G., Gurjar, B. R., Van Aardenne, J., Schultz, M., and Lelieveld, J.: The representation of emissions from megacities in global emission inventories, Atmos. Environ. 42, 703-719, 2008.

Butler, T. M. and Lawrence, M. G.: The influence of megacitieson global atmospheric chemistry: a modelling study, Environ. Chem., 6, 219-225, doi:10.1071/EN08110, 2009.

Butler, T. M., Stock, Z. S., Russo, M. R., Denier van der Gon, H. A. C., and Lawrence, M. G.: Megacity ozone air quality under four alternative future scenarios, Atmos. Chem. Phys., 12, 44134428, doi:10.5194/acp-12-4413-2012, 2012. 
Crippa, M., DeCarlo, P. F., Slowik, J. G., Mohr, C., Heringa, M. F., Chirico, R., Poulain, L., Freutel, F., Sciare, J., Cozic, J., Di Marco, C. F., Elsasser, M., Nicolas, J. B., Marchand, N., Abidi, E., Wiedensohler, A., Drewnick, F., Schneider, J., Borrmann, S., Nemitz, E., Zimmermann, R., Jaffrezo, J.-L., Prévôt, A. S. H., and Baltensperger, U.: Wintertime aerosol chemical composition and source apportionment of the organic fraction in the metropolitan area of Paris, Atmos. Chem. Phys., 13, 961-981, doi:10.5194/acp-13-961-2013, 2013.

Emanuel K. A. and Zivkovic-Rothman, M.: Development and evaluation of a convection scheme for use in climate models, J. Atmos. Sci., 56, 1766-1782, 1999.

Gurjar, B. R. and Lelieveld, J.: New Directions: Megacities and global change, Atmos. Environ., 39, 391-393, 2005.

Gurjar, B. R., Butler, T. M., Lawrence, M. G., and Lelieveld, J.: Evaluation of emissions and air quality in megacities, Atmos. Environ., 42, 1593-1606, 2008.

Guttikunda, S. K. , Carmichael, G. R., Calori, G., Eck, C., and Woo, J. H.: The contribution of megacities to regional sulfur pollution in Asia, Atmos. Environ., 37, 11-22, 2003.

Flanner, M. G., Zender, C. S., Hess, P. G., Mahowald, N. M., Painter, T. H., Ramanathan, V., and Rasch, P. J.: Springtime warming and reduced snow cover from carbonaceous particles, Atmos. Chem. Phys., 9, 2481-2497, doi:10.5194/acp-9-24812009, 2009.

Folberth, G. A., Rumbold, S. T., Collins, W. J., and Butler, T. M.: Global radiative forcing and megacities, Urban Climate, 1, 4-19, 2012.

Forster, C., Stohl, A., and Seibert, P.: Parameterization of convective transport in a Lagrangian particle dispersion model and its evaluation. J. Appl. Meteorl. Climatol., 46, 403-422, doi:10.1175/JAM2470.1, 2007.

Hansen, J. and Nazarenko, L.: Soot climate forcing via snow and ice albedos, P. Natl. Acad. Sci., 101, 423-428, 2004.

Hertel, O., Christensen, J. Runge, E. H., Asman,W. A. H., Berkowicz, R., Hovmand, M. F., and Hov, O.: Development and testing of a new variable scale air pollution model - ACDEP, Atmos. Environ., 29, 1267-1290, 1995.

Hirdman, D., Sodemann, H., Eckhardt, S., Burkhart, J. F., Jefferson, A., Mefford, T., Quinn, P. K., Sharma, S., Ström, J., and Stohl, A.: Source identification of short-lived air pollutants in the Arctic using statistical analysis of measurement data and particle dispersion model output, Atmos. Chem. Phys., 10, 669-693, doi:10.5194/acp-10-669-2010, 2010.

Kunkel, D., Lawrence, M. G., Host, H., Kerkweg, A., Jöckel, P., and Bormann, S.: Urban emissions hot spots as sources for remote aerosol deposition, Geophys. Res. Lett., 39, L01808, doi:10.1029/2011GL049634, 2012.

Lawrence, M. G. and Rasch, P. J.: Tracer transport in deep convective updrafts: plume ensemble versus bulk formulations, J. Atmos. Sci., 62, 2880-2894, 2005.

Lawrence, M. G., Butler, T. M., Steinkamp, J., Gurjar, B. R., and Lelieveld, J.: Regional pollution potentials of megacities and other major population centers, Atmos. Chem. Phys., 7, 39693987, doi:10.5194/acp-7-3969-2007, 2007.

McMahon, T. A. and Denison, P. J.: Empirical atmospheric deposition parameters - a survey, Atmos. Environ., 13, 571-585, 1979.

Mena-Carrasco, M., Carmichael, G. R., Campbell, J. E., Zimmerman, D., Tang, Y., Adhikary, B., D’allura, A., Molina, L. T.,
Zavala, M., García, A., Flocke, F., Campos, T., Weinheimer, A. J., Shetter, R., Apel, E., Montzka, D. D., Knapp, D. J., and Zheng, W.: Assessing the regional impacts of Mexico City emissions on air quality and chemistry, Atmos. Chem. Phys., 9, 3731-3743, doi:10.5194/acp-9-3731-2009, 2009.

Neuman, J. A., Parrish, D. D., Trainer, M., Ryerson, T. B., Holloway, J. S., Nowak, J. B., Swanson, A., Flocke, F., Roberts, J. M., Brown, S. S., Stark, H., Sommariva, R., Stohl, A., Peltiers, R., Weber, R., Wollny, A., Sueper, D. T., Hubler, G., and Fehsenfeld, F. C.: Reactive nitrogen transport and photochemistry in urban plumes over the North Atlantic Ocean, J. Geophys. Res., 111, D23S54, doi:10.1029/2005JD007010, 2006.

Quinn, P. K., Bates, T. S., Baum, E., Doubleday, N., Fiore, A. M., Flanner, M., Fridlind, A., Garrett, T. J., Koch, D., Menon, S., Shindell, D., Stohl, A., and Warren, S. G.: Short-lived pollutants in the Arctic: their climate impact and possible mitigation strategies, Atmos. Chem. Phys., 8, 1723-1735, doi:10.5194/acp8-1723-2008, 2008

Real, E., Law, K. S., Schlager, H., Roiger, A., Huntrieser, H., Methven, J., Cain, M., Holloway, J., Neuman, J. A., Ryerson, T., Flocke, F., de Gouw, J., Atlas, E., Donnelly, S., and Parrish, D.: Lagrangian analysis of low altitude anthropogenic plume processing across the North Atlantic, Atmos. Chem. Phys., 8, 77377754, doi:10.5194/acp-8-7737-2008, 2008.

Riahi, K., Gruebler, A., and Nakicenovic, N.: Scenarios of long-term socio-economic and environmental development under climate stabilization, Technological Forecasting and Social Change, 74, 887-935, 2007.

Roiger, A., Schlager, H., Schäfler, A., Huntrieser, H., Scheibe, M., Aufmhoff, H., Cooper, O. R., Sodemann, H., Stohl, A., Burkhart, J., Lazzara, M., Schiller, C., Law, K. S., and Arnold, F.: Insitu observation of Asian pollution transported into the Arctic lowermost stratosphere, Atmos. Chem. Phys., 11, 10975-10994, doi:10.5194/acp-11-10975-2011, 2011.

Schneider A., Friedl M. A., and Potere D.: A new map of global urban extent from MODIS satellite data, Environ. Res. Lett., 4, 044003, doi:10.1088/1748-9326/4/4/044003, 2009.

Slinn, W. G. N.: Predictions for particle deposition to vegetative canopies. Atmos. Environ., 16, 1785-1794, 1982.

Stohl, A.: Characteristics of atmospheric transport into the Arctic troposphere, J. Geophys. Res., 111, D11306, doi:10.1029/2005JD006888, 2006.

Stohl, A. and Sodemann, H.: characteristics of atmospheric transport into the Antarctic troposphere, J. Geophys. Res., 112, D02305, dio:10.1029/2009JD012536, 2010.

Stohl, A. and Thomson, D. J.: A density correction for Lagrangian particle dispersion models, Bound. Lay. Meteorol., 90, 155-167, doi:10.1023/A:1001741110696, 1999.

Stohl, A., Hittenberger, M., and Wotawa, G.: Validation of the Lagrangian particle dispersion model FLEXPART against largescale tracer experiment data, Atmos. Environ., 32, 4245-4264, doi:10.1016/S1352-2310(98)00184-8, 1998.

Stohl, A., Eckhardt, S., Forster, C., James, P., and Spichtinger, N.: On the pathways and timescales of intercontinental air pollution transport, J. Geophys. Res., 107, 4684, doi:10.1029/2001JD001396, 2002.

Stohl, A., Forster, C., Eckhardt, S., Spichtinger, N., Huntrieser, H., Heland, J., Schlager, H., Wilhelm, S., Arnold, F., and Cooper, O.: A backward modeling study of intercontinental pollution trans- 
port using aircraft measurements, J. Geophys. Res., 108, 4370, doi:10.1029/2002JD002862, 2003.

Stohl, A., Forster, C., Frank, A., Seibert, P., and Wotawa, G.: Technical note: The Lagrangian particle dispersion model FLEXPART version 6.2, Atmos. Chem. Phys., 5, 2461-2474, doi:10.5194/acp-5-2461-2005, 2005.

Stohl, A., Forster, C., Huntrieser, H., Mannstein, H., McMillan, W. W., Petzold, A., Schlager, H., and Weinzierl, B.: Aircraft measurements over Europe of an air pollution plume from Southeast Asia - aerosol and chemical characterization, Atmos. Chem. Phys., 7, 913-937, doi:10.5194/acp-7-913-2007, 2007.

Thomson, D. J.: Criteria for the selection of the stochastic models of particle trajectories in turbulent flows, J. Fluid Mech., 180, 529-556, 1987.
Vignati, E., Karl, M., Krol, M., Wilson, J., Stier, P., and Cavalli, F.: Sources of uncertainties in modelling black carbon at the global scale, Atmos. Chem. Phys., 10, 2595-2611, doi:10.5194/acp-102595-2010, 2010.

Voss, P. B., Zaveri, R. A., Flocke, F. M., Mao, H., Hartley, T. P., DeAmicis, P., Deonandan, I., Contreras-Jiménez, G., MartínezAntonio, O., Figueroa Estrada, M., Greenberg, D., Campos, T. L., Weinheimer, A. J., Knapp, D. J., Montzka, D. D., Crounse, J. D., Wennberg, P. O., Apel, E., Madronich, S., and de Foy, B.: Long-range pollution transport during the MILAGRO-2006 campaign: a case study of a major Mexico City outflow event using free-floating altitude-controlled balloons, Atmos. Chem. Phys., 10, 7137-7159, doi:10.5194/acp-10-7137-2010, 2010.

Wesely, M. L. and Hicks, B. B.: Some factors that affect the deposition rates of sulfur dioxide and similar gases on vegetation, J. Air Poll. Contr. Assoc., 27, 1110-1116, 1977. 